\title{
AS INUNDAÇÕES DE 2009 NA AMAZÔNIA E SUAS RELAÇÕES COM O DESENVOLVIMENTO SUSTENTÁVEL: IMPACTOS AO PRODUTO INTERNO BRUTO MUNICIPAL
}

\author{
Alex Santiago Nina* \\ Universidade Federal do Pará \\ Cláudio Fabian Szlafsztein ${ }^{* *}$ \\ Universidade Federal do Pará
}

\begin{abstract}
Resumo: Nos últimos anos, tem aumentado a frequência dos desastres naturais na Amazônia, concomitantemente com a necessidade de estimar os seus prejuízos econômicos. Este trabalho tem como objetivo verificar qual é o tipo e a intensidade do impacto das inundações de 2009, consideradas as maiores já registradas na Amazônia, no crescimento do Produto Interno Bruto (PIB) municipal. A metodologia consistiu na análise de correlação linear entre o desempenho econômico e algumas variáveis referentes ao tipo de inundação e indicadores socioeconômicos. Os resultados mostram que as inundações bruscas são as mais problemáticas em longo prazo. As principais estratégias a serem adotadas perpassam pela inclusão de ações de mitigação de desastres naturais ao planejamento do desenvolvimento sustentável da Amazônia.
\end{abstract}

Palavras-chave: Produto Interno Bruto. Inundação. Amazônia.

\section{THE 2009 FLOODS IN THE AMAZON AND ITS RELATIONSHIP WITH SUSTAINABLE DEVELOPMENT: IMPACT ON THE MUNICIPAL GROSS DOMESTIC} PRODUCT

Abstract: In the last years, have been increase the frequency of natural disasters in Amazon, concomitantly whit the need of estimate their economic losses. This work have the objective of check what is the type and intensity of 2009 floods impacts, considered the major already registered in Amazon, to the increase of municipal Gross Domestic Product (GDP). The methodology was the linear correlation analysis between the economic performance and some variable relative to inundation type and socioeconomics indicators. The results bring which the fast floods are the major problem in the long term. The means strategies to be adopted are the inclusion of natural disasters mitigation actions in plan of sustainable development of Amazon.

Keywords: Gross Domestic Product. Flood. Amazon.

LAS INUNDACIONES DE 2009 EN LA AMAZONÍA Y SU RELACIÓN CON EL DESARROLLO SOSTENIBLE: IMPACTO EN EL PRODUCTO INTERNO BRUTO MUNICIPAL

Resumen: En los últimos años ha aumentado la frecuencia de los desastres naturales en la Amazonia, concomitantemente con la necesidad de estimar sus prejuicios económicos. Este trabajo tiene como objetivo verificar cual es el tipo y la intensidad del impacto de las inundaciones de 2009, consideradas las mayores ya registradas en la Amazonia, al crecimiento del Producto Bruto Interno (PBI) municipal. La metodología consistió el análisis de correlación linear entre el desempeño económico y algunas variables referentes al tipo de inundación e indicadores socioeconómicos. Los resultados muestran que las inundaciones bruscas son las mas problemáticas a largo plazo. Las principales estrategias a ser adoptadas pasan por la inclusión de acciones de mitigación de desastres naturales a la planificación del desarrollo sostenible de la Amazonia.

Palabras clave: Producto Interno Bruto. Inundaciones. Amazonia. 
Os riscos de desastres naturais tornam-se cada vez mais importantes no contexto geopolítico global, e em consequência cresce a necessidade de inclusão do tema "desastres naturais" nas discussões sobre desenvolvimento. Embora tais eventos sejam tradicionalmente descritos como fenômenos de origem natural, grande parte dos impactos ocorre em virtude de vulnerabilidades das sociedades afetadas associadas, em última instância, ao modelo de desenvolvimento existente (AYSAN; LAVELL, 2014). O conceito de desenvolvimento, por outro lado, tem gerado muitos debates e controversas, principalmente no que diz respeito a sua relação com o crescimento econômico, entendido como o aumento do Produto Interno Bruto (PIB) - a soma, em valores monetários, de todos os bens e serviços finais produzidos numa determinada região durante um período determinado (SATRUSTEGUI, 2013).

Três tipos de correlações econométricas entre o desenvolvimento (manutenção do crescimento econômico), expresso peloPIB, ea ocorrência de desastres naturais à escala internacional são estabelecidas e definidas como negativa, positiva e neutra. As correlações negativas, relatadas em trabalhos de Hochrainer (2009) e Raddatz (2007), ocorrem quando o PIB diminui após eventos de desastres naturais em virtude, entre outros fatores, da redução ou da paralisação da capacidade produtiva, dos danos à infraestrutura, da perda de capital humano decorrente dos feridos e mortos, e do aumento dos custos de assistência emergencial e de recuperação, afetando particularmente os países e regiões menos desenvolvidos.

As correlações positivas acontecem quando o PIB aumenta após a ocorrência de desastres naturais. 0 aumento do PIB pode ser proporcionado, por exemplo, pelo ingresso de recursos externos à região afetada para atividades de resposta ou maior fertilidade do solo decorrente de inundações prolongadas ou em virtude do estímulo gerado por esses eventos ao capital social, às inovações técnicas e ao (re)planejamento das regiões atingidas durante a fase de reconstrução (NOY; VU, 2010; SKIDMORE; TOYA, 2002). As correlações neutras ocorrem quando as análises econométricas não apontam para qualquer tipo de impacto dos desastres naturais ao crescimento do PIB (CAVALLO et al., 2010; JARAMILLO, 2009).

$\mathrm{Na}$ Amazônia, cinco eventos extremos, com aproximadamente 100 anos de período de recorrência, foram registrados em um intervalo de 10 anos: as secas de 2005 e 2010 (MARENGO et al., 2011) e as inundações de 2009, 2012 e 2014 (SENA et al., 2012; ESPINOZA et al., 2015). No Brasil, as inundações são classificadas em dois tipos (graduais e bruscas; conforme o Quadro
1) e contabilizadas por decretos de Situação de Emergência (SE) ou Estado de Calamidade Pública (ECP), emitidos pelo governo do município atingido e reconhecidos pelo governo federal. Este trabalho visa responder aos seguintes questionamentos: os desastres naturais influenciam o crescimento econômico e consequentemente o desenvolvimento dos municípios amazônicos? De que forma ocorre essa influência? Para responder a essas perguntas, consideram-se as inundações ocorridas em 2009, uma das mais intensas já registradas na região.

\section{Desenvolvimento, desastres e produto interno bruto}

A partir do século $X X$, o termo "desenvolvimento" originou três escolas de pensamento: neoclássica, pós-desenvolvimentista e sustentável (SATRUSTEGUI, 2013; SOARES JR.; QUINTELLA, 2008). A escola neoclássica conceitua 0 desenvolvimento como sinônimo de crescimento econômico, baseada na teoria dos "benefícios mútuos", para a qual o aumento da produtividade global provoca uma melhoria no bemestar dos países (MANKIW, 2009). Admite-se que o crescimento do PIB provoca uma redução da pobreza absoluta, maior acesso da população à educação e consciência ambiental - consequentemente há uma redução dos danos provenientes de desastres naturais, em virtude do aumento da renda e do maior investimento em obras preventivas (LOMBORG, 2004).

A escola pós-desenvolvimentista se origina de um conjunto de críticas ao uso do PIB como indicador do desenvolvimento, considera que o conceito de desenvolvimento é complexo e não linear, e, portanto, impossível de ser mensurado por qualquer indicador (SOARES JR.; QUINTELLA, 2008). Alguns teóricos consideram que 0 crescimento do PIB acentua as desigualdades e a segregação socioespacial, aumentando a vulnerabilidade aos desastres naturais (MATTEDI; BUTZKE, 2001). A terceira escola surge de uma reformulação da ideia de desenvolvimento em virtude das críticas levantadas pela escola pós-desenvolvimentista à escola neoclássica. Nesse sentido, acresce-se o adjetivo "sustentável" ao desenvolvimento. Esta escola visa ao crescimento concomitante dos capitais natural, social e econômico, visto que não existe uma relação de substituição perfeita entre eles (KESTEMONT, 2010). Na visão da sustentabilidade, o crescimento econômico por si só, embora necessário, não garante a prevenção dos desastres naturais (AYSAN; LAVELL, 2014). 
Quadro 1 - Tipos de inundações conforme suas principais condicionantes naturais no Brasil.

\begin{tabular}{|c|c|c|}
\hline \multirow{2}{*}{ Condicionante Natural } & \multicolumn{2}{|c|}{ Inundação } \\
\hline & Gradual & Brusca \\
\hline $\begin{array}{l}\text { Velocidade de } \\
\text { precipitação }\end{array}$ & $\begin{array}{l}\text { Menor que a velocidade de } \\
\text { infiltração no solo. }\end{array}$ & $\begin{array}{l}\text { Maior que a velocidade infiltração } \\
\text { no solo. }\end{array}$ \\
\hline Escoamento superficial & $\begin{array}{c}\text { A água contribui para o } \\
\text { escoamento superficial após } \\
\text { infiltração e saturação do solo. }\end{array}$ & $\begin{array}{l}\text { A água contribui diretamente } \\
\text { para o escoamento superficial. }\end{array}$ \\
\hline Origem & $\begin{array}{l}\text { Chuvas frontais de baixa } \\
\text { intensidade e longa duração. }\end{array}$ & $\begin{array}{c}\text { Chuvas convectivas ou } \\
\text { orogenéticas de alta intensidade } \\
\text { e curta duração. }\end{array}$ \\
\hline Geomorfologia regional & $\begin{array}{l}\text { Altitude e declividade baixas, } \\
\text { substrato permeável e } \\
\text { cobertura vegetal densa. }\end{array}$ & $\begin{array}{l}\text { Altitude e declividade altas, } \\
\text { substrato pouco permeável e } \\
\text { escassa cobertura vegetal. }\end{array}$ \\
\hline Superfície afetada & $\begin{array}{c}\text { Grande, provoca impactos } \\
\text { ecológicos. }\end{array}$ & $\begin{array}{c}\text { Reduzida, provoca processos de } \\
\text { erosão. }\end{array}$ \\
\hline
\end{tabular}

Fonte: adaptado de BRASIL (2003).

\section{Inundações ocorridas em 2009 na Amazônia}

As inundações ocorridas na Amazônia em 2009 se caracterizaram pela sua grande extensão geográfica e intensidade dos impactos, originadas por chuvas abundantes durante o verão (dezembro de 2008 a fevereiro de 2009) e o aumento dos níveis dos rios entre março e maio de 2009. 0 volume das precipitações foi superior ao dos eventos de grande magnitude em 19881989 e 1998-1999, tendo sido os estados do Amazonas e do Pará os mais afetados (Figura 1) (MARENGO et al., 2011b).

As inundações de 2009 afetaram 2.380.000 mil moradores próximos às margens do rio Amazonas e seus tributários - choveu mais do que o esperado em diversas cidades da região como Parauapebas, Marabá, Santarém, Alenquer, dentre outras (FILIZOLA et al., 2013). $\mathrm{Na}$ cidade de Manaus, grande parte da zona urbana foi inundada por 244 dias com cotas do nível do rio de 29,77m, a maior até então registrada em 107 anos de monitoramento (CPRM, 2009).

\section{Metodologia}

Os dados, levantados para os municípios do Amazonas e do Pará, foram: a lista dos atingidos por inundações em 2009 com portaria de reconhecimento de SE e ECP, disponível no site do Ministério da Integração Nacional (BRASIL, 2015a); indicadores socioeconômicos (para o período de 2005 a 2012), tais como PIB, população, Índice de Desenvolvimento Humano (IDH), Índice de Gini, pobreza absoluta e renda média, disponíveis no site do Instituto Brasileiro de Geografia e Estatística (IBGE, 2015a); receitas (Rc) e transferências (Tc) orçamentárias, disponíveis no site do Sistema Integrado de Administração Financeira do Governo Federal (SIAFI) (BRASIL, 2015b). Ressalta-se que os valores monetários absolutos do PIB, receitas e transferências correspondem a valores correntes em 2014 - os mais atuais para o período em que foi feita a coleta dos dados (IBGE, 2015b). A metodologia foi dividida em quatro etapas. 
Figura 1 - Localização da Amazônia brasileira, destacando os estados mais atingidos pelas inundações de 2009 Amazonas e Pará.

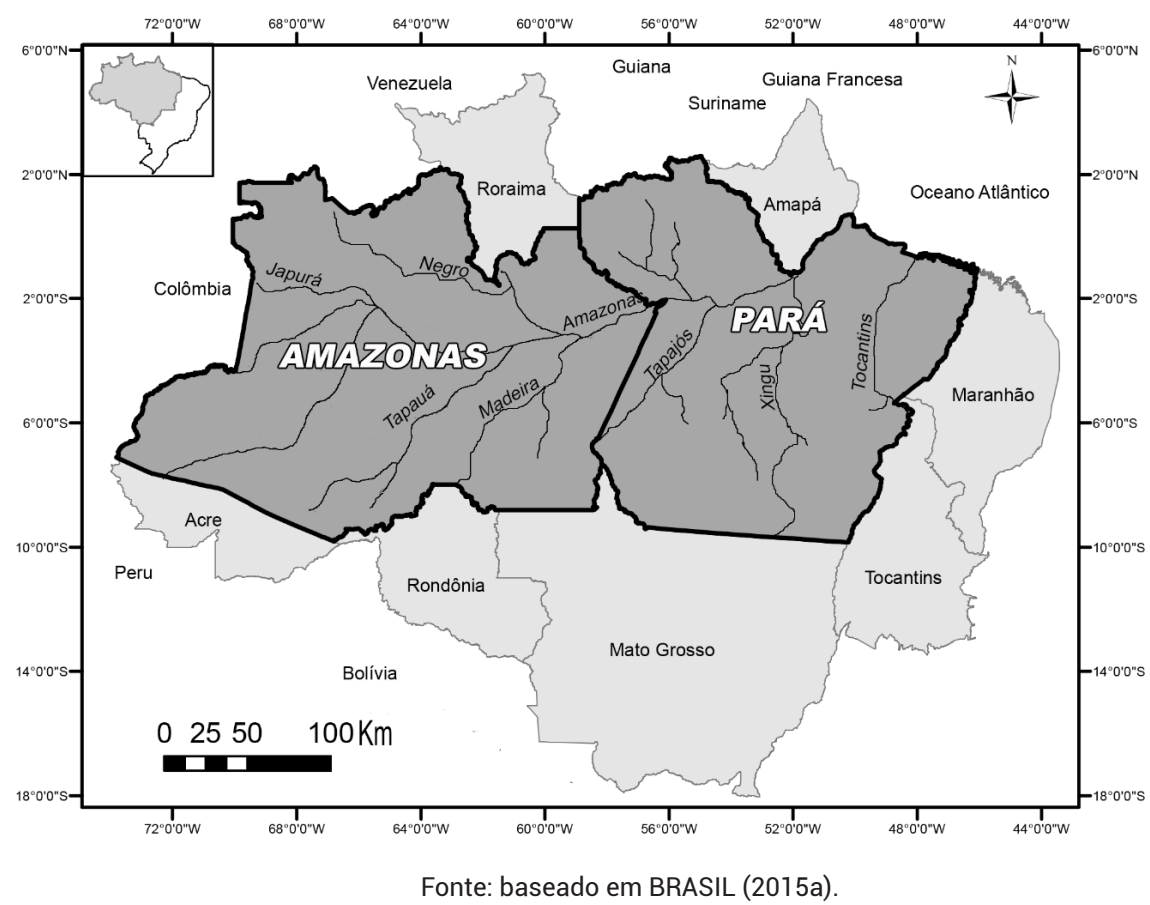

\section{Cálculo da equação estacionária da série temporal do PIB dos municípios (2005-2008)}

A equação estacionária é um modelo de ajuste de uma função aos dados históricos de uma série temporal, utilizado para estimar valores posteriores a esta série (GUJARATI; POTTER, 2011). Neste trabalho, a equação foi calculada a partir da série temporal do PIB dos municípios no período anterior à inundação (2005-2008) através do método Autorregressivo Integrado de Média Móvel (ARIMA), utilizado por Hochrainer (2009) e Xiao (2011). O método ARIMA de autocorrelação multivariada utiliza como variável dependente $Y_{t}$ e como variáveis explanatórias valores defasados de $Y_{t}\left(Y_{t-p^{\prime}}, Y_{t-2^{\prime}}, Y_{t-3^{\prime}} \ldots\right.$, $\left.Y_{t-m}\right)$, de acordo com a seguinte equação:

$$
\left(Y_{t}-Y_{t-n}\right)=\Theta+\alpha_{1}\left(Y_{t-1}-Y_{t-n-1}\right)+\alpha_{2}\left(Y_{t-2}-Y_{t-n-2}\right)+\ldots+\alpha_{m}\left(Y_{t-m}-Y_{t-n-m}\right)
$$

Equação 1

$$
+\mathrm{B}_{0} \mu_{\mathrm{t}}+\mathrm{B}_{1} \mu_{\mathrm{t}-1}+\mathrm{B}_{2} \mu_{\mathrm{t}-2}+\ldots+\mathrm{B}_{\mathrm{p}} \mu_{\mathrm{t}-\mathrm{p}}
$$

\section{$\theta$ é uma constante}

$Y$ é a variável da série temporal

$t$ é o tempo

$\alpha$ e B são coeficientes de correlação

$\mu$ é o erro estocástico (parcela da variável dependente não explicada pelas variáveis explanatórias do modelo)

$n$ é a ordem de defasagem inicialmente utilizada para a variável $Y$ $m$ e $p$ correspondem às ordens de defasagens finais de $Y$ e $\mu$, respectivamente

A definição da ordem das defasagens $(m, n, p)$ mais adequadas baseou-se no critério de informação de Alkaika (CIA):

$$
\mathrm{ClA}=\mathrm{e}^{2 \mathrm{k} / \mathrm{n}} \underline{\underline{\mu}}{ }^{2} / \mathrm{a} \quad \text { Equação } 2
$$

$k$ é o número de regressores da equação $a$ é o tamanho da amostra (número de municípios) $\mu$ é o erro estocástico

\section{Cálculo do desempenho econômico por município}

O desempenho econômico absoluto e relativo de cada município é a diferença entre o PIB "esperado" e o "observado" para o período 2009-2012. O PIB "observado" é o medido pelo IBGE, enquanto que o PIB "esperado" corresponde à previsão feita para o período 2009-2012 a partir da equação estacionária da série temporal do PIB de 2005-2008 para cada município (Quadro 2; Figura 2). 


\begin{tabular}{|c|c|}
\hline Desempenho Econômico Absoluto (DEA) & Desempenho Econômico Relativo (DER) \\
\hline DAR = PIBobs - PIBesp & DER $=\frac{(\text { PIBobs }- \text { PIBesp })}{\text { PIBobs }} * 100$ \\
\hline $\begin{array}{r}\text { PIBobs = PIB municipal obse } \\
\text { PIBesp = PIB municipal esperad }\end{array}$ & $\begin{array}{l}\text { vado nos anos } 2009 \text { a } 2012 \\
\text { o para os anos de } 2009 \text { a } 2012\end{array}$ \\
\hline
\end{tabular}

Figura 2 - Representação do desempenho econômico positivo e negativo (absoluto e relativo).

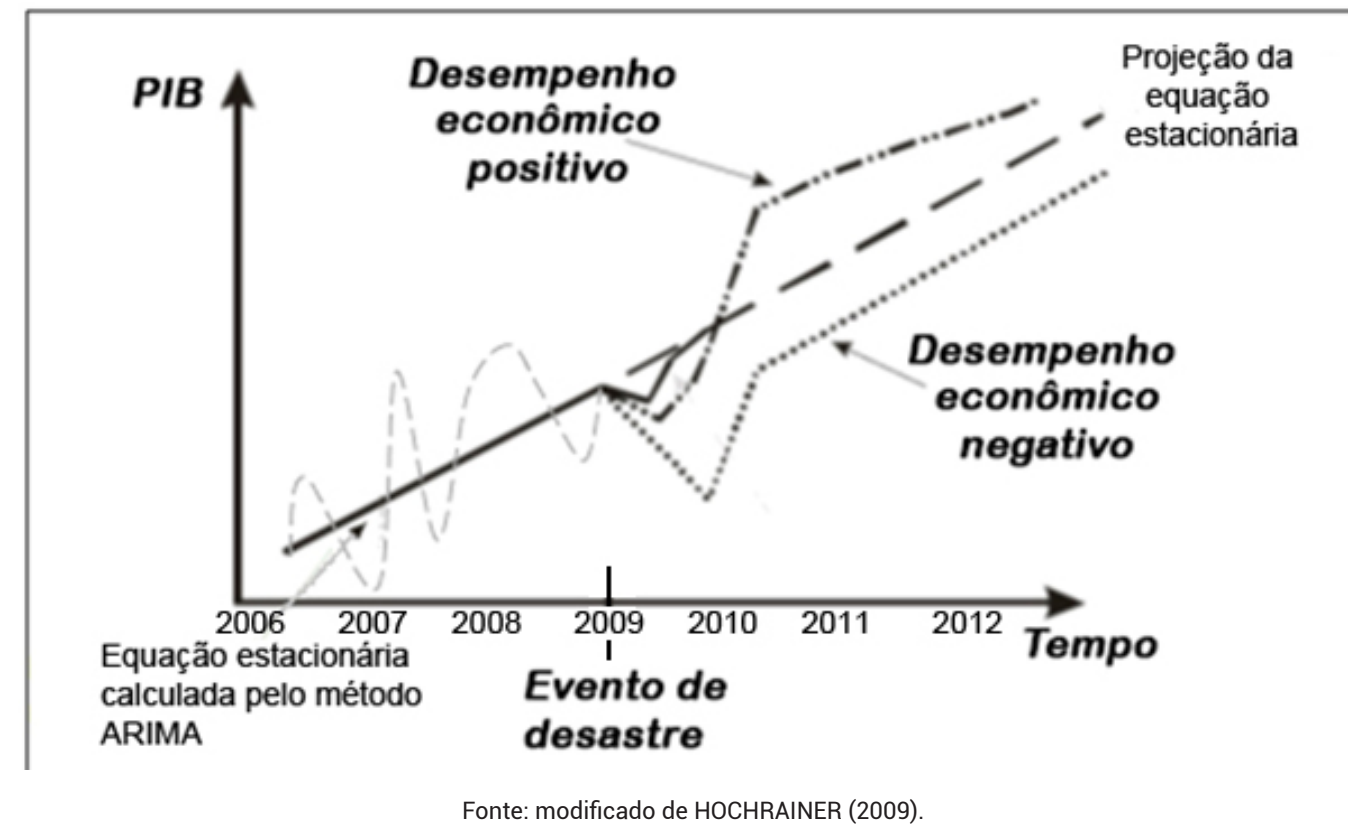

Análise de correlação do desempenho econômico com variáveis qualitativas e quantitativas

A análise de correlação linear seguindo o Método dos Mínimos Quadrados Ordinários (MQO) objetiva estimar a influência de uma variável explanatória $X$ a uma variável dependente $Y$, com base em dois termos: a) Coeficiente Angular $(\beta)$ - a alteração da variável dependente $Y$ para cada alteração de uma unidade da variável explanatória. Quanto maior o módulo de $\beta$, maior a relevância da variável explanatória; b) Nível de Significância (p) - a probabilidade de o coeficiente angular ser igual a 0 (hipótese nula), considerando-se significativos quando $\mathrm{p}$ $\leq 5 \%$. Quanto menor $p$, maior a significância da variável explanatória (GUJARATI; PORTER, 2011).
Adotaram-se variáveis explanatórias qualitativas e quantitativas (Quadro 3) com base na literatura (CUTTER et al., 2003; NOY; VU, 2010) e na disponibilidade de dados. Como variáveis dependentes utilizou-se o desempenho econômico de cada um dos municípios (absoluto e relativo) entre 2009-2012 no caso das correlações com variáveis explanatórias qualitativas, e apenas para 2009, no caso das correlações com variáveis explanatórias quantitativas. 
Quadro 3 - Variáveis explanatórias usadas na análise de regressão.

\begin{tabular}{|c|c|c|c|c|}
\hline $\begin{array}{c}\text { Natureza da } \\
\text { variável }\end{array}$ & \multicolumn{2}{|r|}{ Variáveis } & Fonte & Sigla \\
\hline \multirow{13}{*}{ Qualitativa } & \multirow{13}{*}{ Municípios } & $\begin{array}{l}\text { Localizados nos estados do Pará e do } \\
\text { Amazonas }\end{array}$ & \multirow{13}{*}{$\begin{array}{c}\text { Secretaria } \\
\text { Nacional } \\
\text { de Defesa } \\
\text { Civil } \\
\text { (BRASIL, } \\
2015 a)\end{array}$} & $\mathrm{Td}$ \\
\hline & & Nāo atingidos por inundaçōes & & $S$ \\
\hline & & Atingidos por inundaçōes & & $\mathrm{D}$ \\
\hline & & Atingidos por inundaçōes graduais & & $\lg$ \\
\hline & & Atingidos por inundaçōes bruscas & & $\mathrm{Ib}$ \\
\hline & & Localizados no Estado do Amazonas & & $\mathrm{Am}$ \\
\hline & & Localizados no Estado do Pará & & $\mathrm{Pa}$ \\
\hline & & $\begin{array}{l}\text { Localizados no Estado do Amazonas e } \\
\text { atingidos por inundaçōes }\end{array}$ & & Aml \\
\hline & & $\begin{array}{l}\text { Localizados no Estado do Pará e atingidos por } \\
\text { inundaçōes }\end{array}$ & & Pal \\
\hline & & $\begin{array}{l}\text { Localizados no Estado do Amazonas e } \\
\text { atingidos por inundaçōes graduais }\end{array}$ & & Amlg \\
\hline & & $\begin{array}{l}\text { Localizados no Estado do Amazonas e } \\
\text { atingidos por inundaçōes bruscas }\end{array}$ & & Amlb \\
\hline & & $\begin{array}{l}\text { Localizados no Estado do Pará e atingidos por } \\
\text { inundaçōes graduais }\end{array}$ & & Palg \\
\hline & & $\begin{array}{l}\text { Localizados no Estado do Pará e atingidos por } \\
\text { inundaçōes bruscas }\end{array}$ & & Palb \\
\hline & Produto Int & erno Bruto em 2008 (R\$) & & PIB \\
\hline & Área $\left(\mathrm{km}^{2}\right)$ & & & $\mathrm{T}$ \\
\hline & Populaçāo & 2010 (número de habitantes) & & Po \\
\hline & Produto Int & erno Bruto per capita (R\$/habitantes) & & $\mathrm{PIBc}$ \\
\hline & Densidade & oopulacional (habitantes $/ \mathrm{km}^{2}$ ) & & $\mathrm{Dp}$ \\
\hline Quantitativa & $\begin{array}{l}\text { Índice de } \\
\text { (de } 0-\text { mer }\end{array}$ & $\begin{array}{l}\text { esenvolvimento Humano Municipal em } 2010 \\
\text { los desenvolvido a } 1 \text { - mais desenvolvido) }\end{array}$ & IBGE & IDHm \\
\hline & $\begin{array}{l}\text { Renda M } \\
\text { (R\$/habitar }\end{array}$ & $\begin{array}{lllll}\text { édia } & \text { Municipal per capita em } 2010 \\
\text { tes) } & & & & \\
\end{array}$ & & $\operatorname{Re}$ \\
\hline & $\begin{array}{l}\text { İndice de } \\
\text { habitantes }\end{array}$ & $\begin{array}{l}\text { Pobreza Absoluta em } 2003 \text { (percentual de } \\
\text { abaixo de "linha da pobreza"*) }\end{array}$ & & PB \\
\hline & $\begin{array}{l}\text { Índice de G } \\
\text { - mais des }\end{array}$ & $\begin{array}{l}\text { ini em } 2003, \text { social (de } 0-\text { menos desigual a } 1 \\
\text { gual) }\end{array}$ & & G \\
\hline
\end{tabular}

*A linha de pobreza é uma estimativa feita pela Organização das Nações Unidas do valor de uma cesta de alimentos com o mínimo de calorias necessárias para suprir adequadamente uma pessoa. 
Para Xiao (2011) existe a necessidade que análises de impactos de desastres naturais ao PIB considerem as fontes externas das receitas dos governos municipais. No contexto Amazônico, tal variável torna-se ainda mais importante, uma vez que estas verbas representam aproximadamente $70 \%$ dos orçamentos municipais (TRINDADE e OLIVEIRA, 2013). Nesse sentido, foi feita uma análise de correlação econométrica linear (MQO), utilizando-se como variável dependente a diferença entre Receitas (Rc) e Transferências (Tc) correntes de 2009 e de 2008, tanto em termos absolutos como relativos (Quadro 4); e as variáveis explanatórias qualitativas apresentadas no Quadro 3. Municípios sem contas no SIAFI foram desconsiderados.

Quadro 4 - Cálculo da Diferença das Receitas e Transferências (Absolutas e Relativas) entre os anos de 2009 e 2008 . Transferências Correntes em 2009 (Tc2009) e em 2008 (Tc2008), Receita Corrente em 2009 (Rc2009) e em 2008 (Rc2009). Diferença da Receita (DRA) e da Transferência (DTA) Absoluta. Diferença da Receita (DRR) e da Transferência (DTR).

\begin{tabular}{|c|c|}
\hline Diferenças Absolutas & Diferenças Relativas \\
\hline DRA = Rc2009 - Rc2008 & DRR $=\left(\frac{\operatorname{Rc} 2009-\mathrm{Rc} 2008)}{\mathrm{Rc} 2008} * 100\right.$ \\
\hline DTA = Tc2009 - Tc2008 & $\mathrm{DTR}=\left(\frac{\mathrm{Tc} 2009-\mathrm{Tc} 2008)}{\mathrm{Tc} 2008} * 100\right.$ \\
\hline
\end{tabular}

\section{Resultados}

Os resultados mostram que 77 (38\%) dos 205 municípios estudados foram atingidos por inundações em 2009, 56 (28\%) por inundações graduais e $21(10 \%)$ por inundações bruscas; 36 (58\%) dos 62 municípios do Amazonas registraram inundações graduais e nenhum deles inundações bruscas; 20 (14\%) dos 143 municípios do Pará registraram inundações graduais e 21(15\%) inundações bruscas (Figura 3).
As inundações graduais ocorreram predominantemente nas regiões central e sul do estado do Amazonas e noroeste e sul do estado do Pará; enquanto que as inundações bruscas predominaram no sudeste e sudoeste paraense (Figura 3 ). Todas as inundações ocorreram no primeiro semestre de 2009, destacando-se o mês de fevereiro, quando abrangeram cerca de $32 \%$ dos municípios inundados (Figura 4).

Os municípios do Pará e do Amazonas tiveram desempenho econômico, em média, abaixo do esperado em 2009. Os prejuízos totalizaram cerca de $\mathrm{R} \$ 7,7$ milhões, sendo que aproximadamente R\$ 6 milhões (cerca de $80 \%$ ) ocorreram em municípios atingidos por inundações (Figura 5; Tabela 1). 
Figura 3 - Municípios atingidos por inundações graduais e bruscas nos estados do Amazonas e do Pará em 2009. Os municípios estão designados por números conforme o Anexo $\mathrm{A}$.

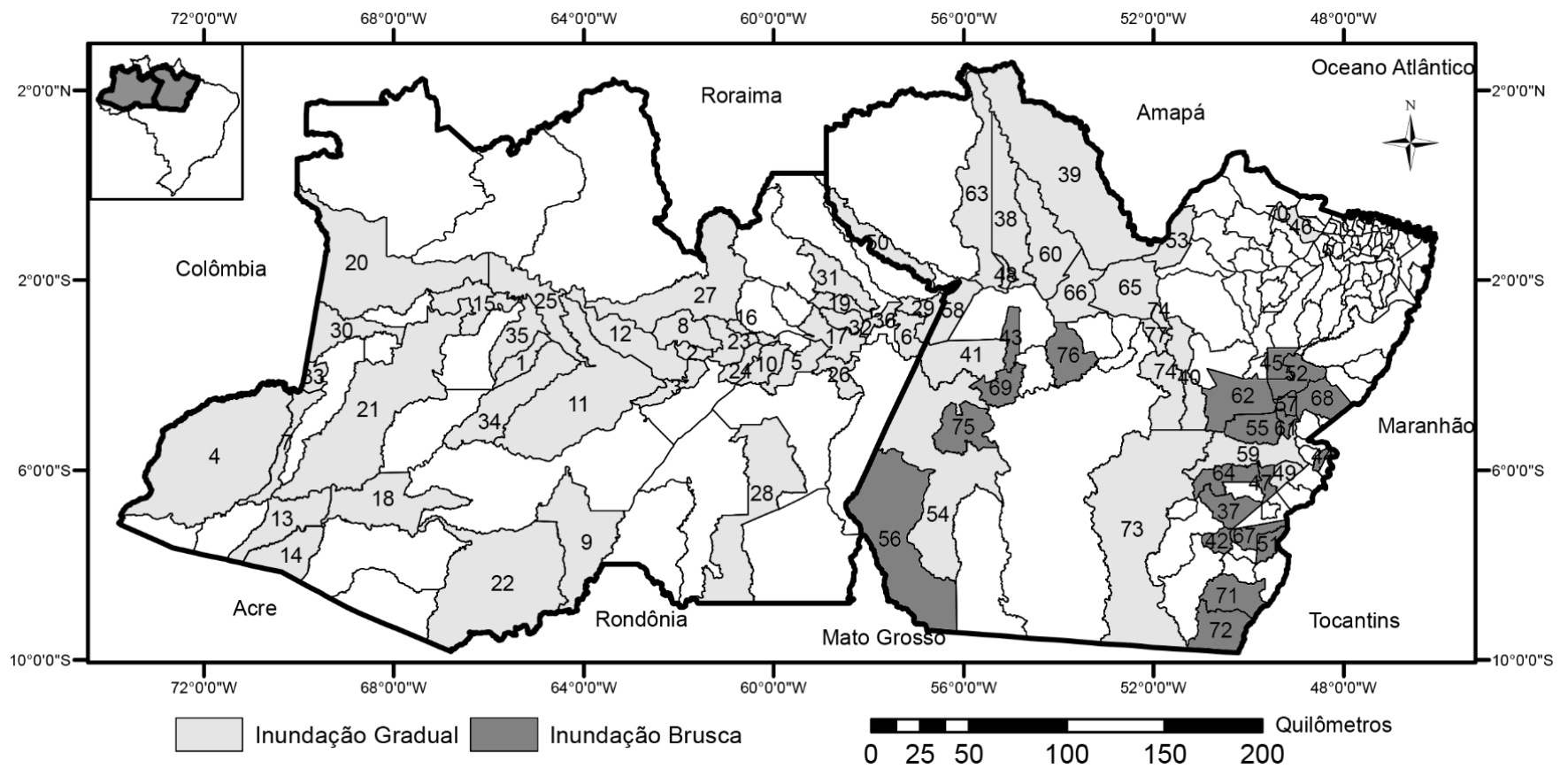

Fontes dos dados: IBGE (2015a) e BRASIL (2015a).

Figura 4 - Percentual de municípios de acordo com o mês de ocorrência da inundação no ano de 2009.

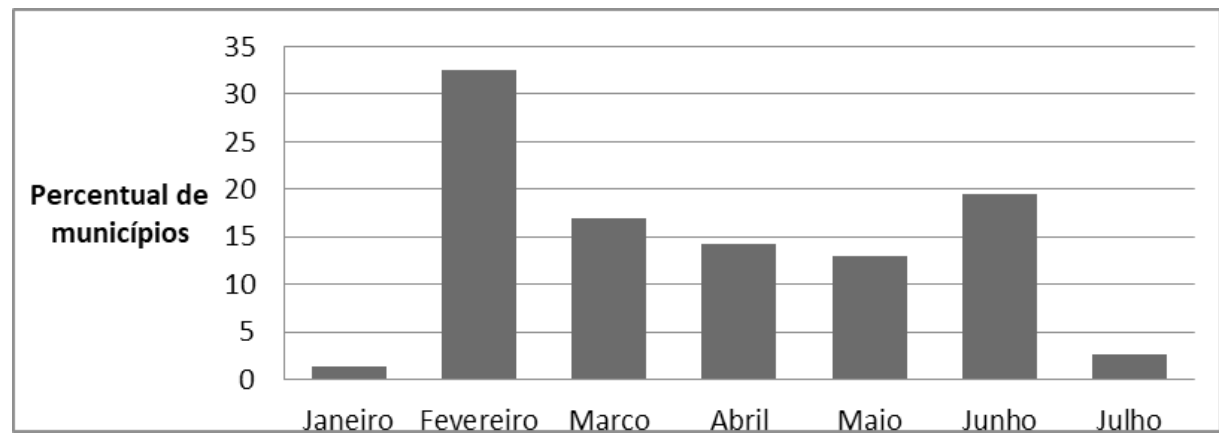

Fonte: BRASIL (2015a) 
Os municípios do Pará e do Amazonas tiveram desempenho econômico, em média, abaixo do esperado em 2009. Os prejuízos totalizaram cerca de $\mathrm{R} \$$ 7,7 mi-
Ihões, sendo que aproximadamente R\$ 6 milhões (cerca de $80 \%$ ) ocorreram em municípios atingidos por inundações (Figura 5; Tabela 1).

Figura 5 - Municípios atingidos por inundações no Amazonas e no Pará em 2009, classificados segundo o desempenho econômico. Os municípios estão designados por números conforme o Anexo A.

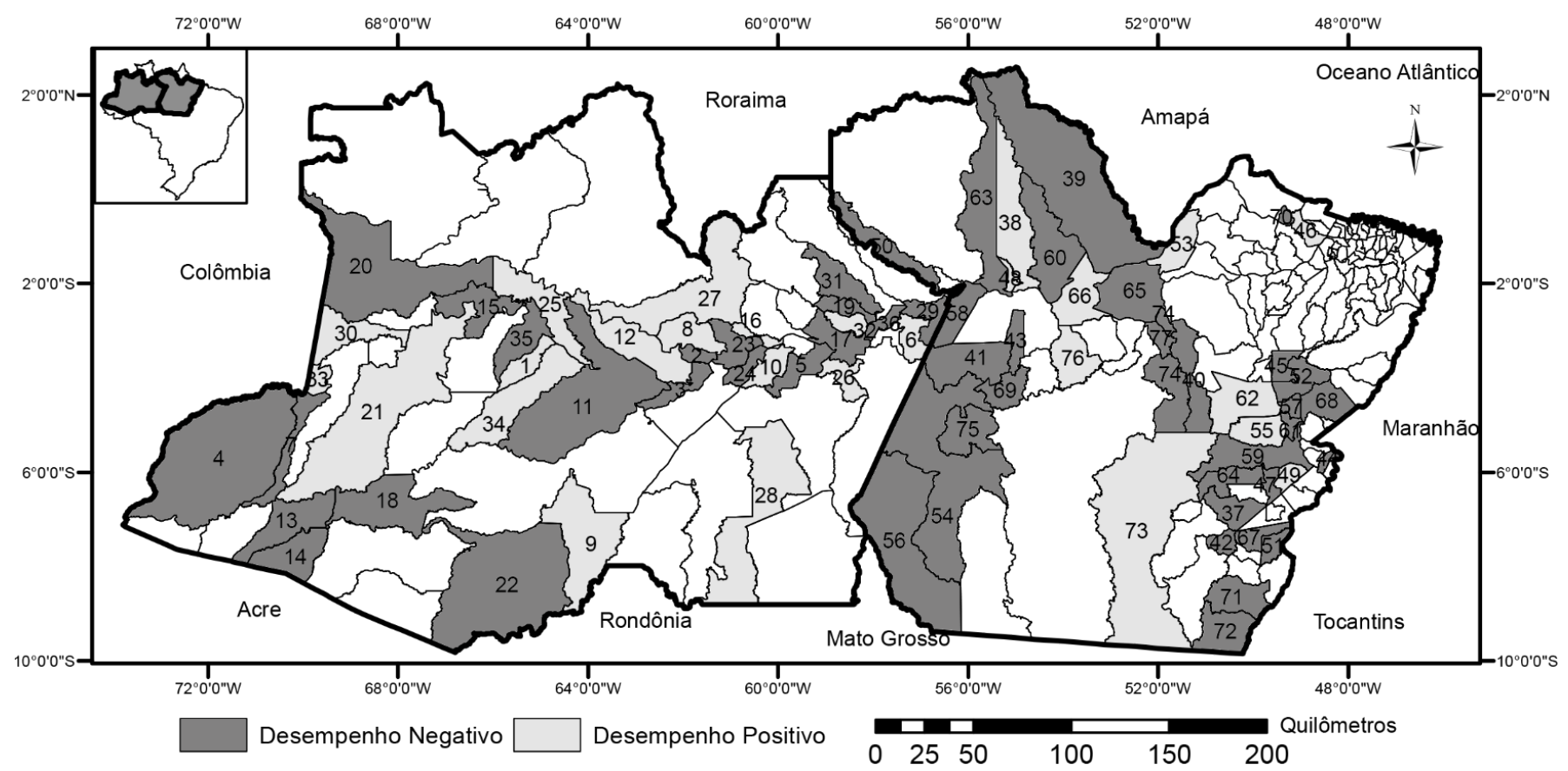

Fontes dos dados: IBGE (2015a) e BRASIL (2015a).

Tabela 1 - Desempenho Econômico Absoluto de todos os municípios dos estados do Pará e do Amazonas (Td), com registro de todo tipo de inundações (D); Graduais (Ig) e Bruscas (Ib) em 2009

\begin{tabular}{c|c|c|c|}
\multirow{2}{*}{ Municípios } & \multirow{2}{*}{ Total (R\$̦) } & \multicolumn{2}{|c|}{ Estado } \\
\cline { 3 - 4 } & & Amazonas (R\$̦) & Pará (R\$) \\
\hline Td & $-7.705 .434,43$ & $-849.369,18$ & $-6.856 .065,25$ \\
D & $-5.995 .008,11$ & $-1.254 .632,77$ & $-4.740 .375,35$ \\
Ig & $-3.441 .462,22$ & $-1.254 .632,77$ & $-2.186 .829,46$ \\
Ib & $-2.553 .545,89$ & - & $-2.553 .545,89$ \\
\hline
\end{tabular}

Fontes dos dados: IBGE (2015a) e BRASIL (2015a). 
Considerando todos os municípios estudados, o prejuízo econômico absoluto médio em 2009 foi de R\$ $37,5 \mathrm{mil} /$ município $(-3,68 \%$ em termos relativos em relação ao PIB), mas, considerando apenas os municípios atingidos por inundações, este prejuízo se incrementa, alcançando $\mathrm{R} \$ 77,9 \mathrm{mil} /$ municípios $(-7,91 \%$ em termos relativos em relação ao PIB). Essa situação se agrava em caso de municípios localizados no Pará e atingidos por inundações bruscas, quando o prejuízo médio alcança $\mathrm{R} \$ 121,6 \mathrm{mil} /$ município $(-11,46 \%$ em termos relativos) (Tabela 2).

Tabela 2 - Média do Desempenho Econômico Absoluto e Relativo em 2009 dos municípios estudados (Td), municípios com registro de inundações (D); Graduais (Ig); Bruscas (Ib), e Sem registro (S).

\begin{tabular}{|c|c|c|c|c|c|c|}
\hline \multirow{3}{*}{ Município } & \multirow{2}{*}{\multicolumn{2}{|c|}{ Total }} & \multicolumn{4}{|c|}{ Estado } \\
\hline & & & \multicolumn{2}{|c|}{ Amazonas } & \multicolumn{2}{|c|}{ Pará } \\
\hline & R\$/município & \%/município & R\$/município & \%/município & R\$/município & \%/município \\
\hline $\mathrm{Td}$ & -37.587 & $-3,68$ & -13.699 & $-2,68$ & -47.944 & $-4,11$ \\
\hline$S$ & -13.362 & $-1,13$ & 15.587 & $-0,83$ & -20.742 & $-1,21$ \\
\hline $\mathrm{D}$ & -77.857 & $-7,91$ & -34.850 & $-4,01$ & -115.618 & $-11,32$ \\
\hline $\lg$ & -61.454 & $-6,57$ & -34.850 & $-4,01$ & -109.341 & $-11,18$ \\
\hline $\mathrm{Ib}$ & -121.597 & $-11,46$ & - & - & -121.597 & $-11,46$ \\
\hline
\end{tabular}

Fontes dos dados: IBGE (2015a) e BRASIL (2015a).

Nos municípios atingidos por inundações, os prejuízos econômicos em 2009 foram resultantes de pelo menos dois fatores: a) a tendência regional de desempenho econômico abaixo do esperado, comum tanto aos municípios atingidos como aos não atingidos e provavelmente relacionada à crise econômica internacional de 2008 (LEAL et al., 2012); b) a ocorrência do desastre natural como fator significativo na determinação do desempenho econômico do município. Embora tanto os municípios atingidos como os não atingidos tenham apresentado uma queda em 2009, nos primeiros a redução foi maior, de modo que o PIB médio foi menor que no ano anterior (Figura 6).

Figura 6 - Variação da média do PIB dos municípios entre 2005 e 2012. T = todos os municípios; D = municípios atingidos por inundações; $S$ = municípios não atingidos por inundações.

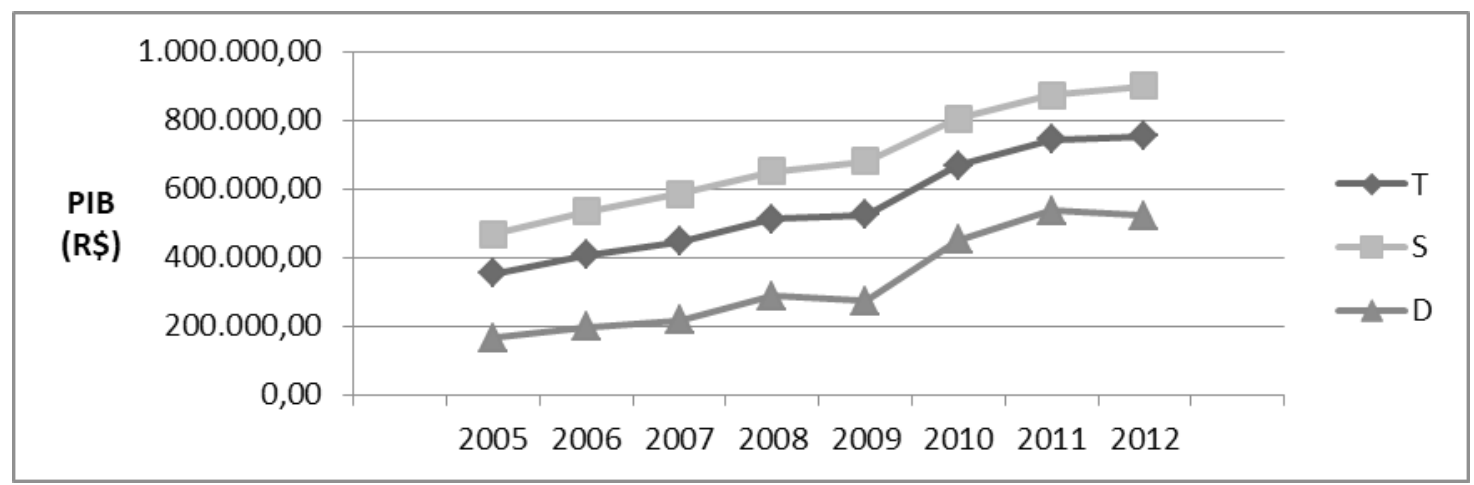

Fonte dos dados: BRASIL (2015a e b). 
Uma limitação inerente aos dados coletados é o fato de que nem todos os municípios onde ocorreram prejuízos decorrentes de inundações declaram SE ou $E C P$, de modo que dentre os municípios mais ricos e dotados de recursos próprios é maior a probabilidade de que esses instrumentos não sejam utilizados. Foi o caso do município de Manaus, que, mesmo tendo sido atingido por uma inundação histórica, não emitiu declaração. Por outro lado, não necessariamente a probabilidade de declaração de SE ou ECP é maior nos municípios mais pobres - pelo contrário, nestes municípios, a falta de capacitação técnica e recursos financeiros constituem um dos principais problemas (VENTURATO-LANDMAM; VALENCIO, 2014).

Além disso, outras dificuldades também contribuem para aumentar a vulnerabilidade dos municípios aos desastres naturais: a não continuidade das políticas públicas; a fragilidade da sociedade civil, apresentando altos índices de pobreza absoluta e baixos índices de educação e renda, e dificultando a promoção da gestão participativa; a alta rotatividade dos funcionários; a impunidade aos crimes (ambientais, fiscais, dentre outros); a crença da origem estritamente natural dos desastres, o que faz com que muitos gestores não adotem estratégias de redução das vulnerabilidades para minimização dos riscos naturais (SIMONI et al., 2013; SZLAFSZTEIN, 2015).

Somada a isso, tem-se a falta de integração das políticas públicas. 0 Estado do Pará, por exemplo, não possui política de mudanças climáticas, em contraste com os estados do Acre e do Amazonas. Essas políticas proporcionam um estímulo ao planejamento de modelos de desenvolvimento regional sustentável; à promoção e regulamentação de mecanismo de desenvolvimento de matriz energética limpa e educação ambiental; à criação de novas unidades de conservação (SZLAFSZTEIN, 2015).
Correlações do desempenho econômico absoluto e relativo com variáveis qualitativas

Somente em 2009, o desempenho econômico (absoluto e relativo) dos municípios atingidos pelas inundações foi estatisticamente menor em comparação com o dos municípios não atingidos. 0 efeito das inundações foi mais intenso em 2009 provavelmente devido ao fato de esses eventos terem ocorrido no primeiro semestre do ano, de modo que no ano de 2010 (pelo menos seis meses após a ocorrência da inundação), os municípios, no geral, retornaram ao seu nível de crescimento pré-desastre. Isso, no entanto, não ocorreu para os municípios atingidos por inundações bruscas, onde prejuízos perduraram até 2012. Esses resultados estão sintetizados no Quadro 5 e detalhados no Anexo B.

Esse impacto mais duradouro relaciona-se às características naturais das inundações bruscas - ocorrem de forma repentina e de previsão mais difícil (em relação às graduais), além de acentuarem tanto a velocidade dos rios (e sua força destrutiva) como os processos erosivos. Por outro lado, fatores socioeconômicos não devem ser desconsiderados. Os municípios atingidos pelas inundações bruscas, como Parauapebas, caracterizam-se por serem relativamente ricos e populosos no contexto amazônico, e possuírem modelos de desenvolvimento associados à ocupação do território incentivada por grandes projetos de mineração desde a década de 1980. Tal ocupação, no entanto, não foi acompanhada de um planejamento adequado e melhoria da qualidade de vida das pessoas, resultando no povoamento de zonas perigosas por populações socialmente vulneráveis às inundações (LEAL et al., 2012). 
Quadro 5 - Síntese dos resultados das correlações dos desempenhos econômicos (absoluto e relativo) com variáveis qualitativas no período 2009 a 2012. Desempenho Econômico Relativo (DER) e Absoluto (DEA). O Anexo B demonstra os resultados detalhados.

\begin{tabular}{|c|c|c|c|c|}
\hline \multirow{2}{*}{$\begin{array}{c}\text { Diferença significativa entre os } \\
\text { desempenhos econômicos dos } \\
\text { municípios }\end{array}$} & \multicolumn{4}{|c|}{ Ano } \\
\hline & 2009 & 2010 & 2011 & 2012 \\
\hline $\begin{array}{l}\text { Atingidos e nāo atingidos por } \\
\text { inundaçōes }\end{array}$ & Sim & Nāo & Nāo & Nāo \\
\hline Localizados no Pará e no Amazonas & Nāo & Nāo & Nāo & Nāo \\
\hline $\begin{array}{l}\text { Atingidos por inundaçōes graduais e } \\
\text { nāo atingidos por inundaçōes }\end{array}$ & Nāo & Nāo & Nāo & Nāo \\
\hline $\begin{array}{l}\text { Atingidos por inundaçōes bruscas e } \\
\text { nāo atingidos por inundaçōes }\end{array}$ & Sim & Sim & Sim & $\begin{array}{l}\text { Somente } \\
\text { para DEA }\end{array}$ \\
\hline $\begin{array}{l}\text { Localizados no Pará e no Amazonas } \\
\text { e atingidos por inundaçōes }\end{array}$ & Nāo & Nāo & Nāo & Nāo \\
\hline $\begin{array}{l}\text { Atingidos por inundaçōes bruscas e } \\
\text { graduais }\end{array}$ & Nāo & $\begin{array}{l}\text { Somente } \\
\text { para DER }\end{array}$ & Nāo & Nāo \\
\hline $\begin{array}{l}\text { No Amazonas, atingidos e nāo } \\
\text { atingidos por inundaçōes }\end{array}$ & Nāo & Nāo & Nāo & Nāo \\
\hline $\begin{array}{l}\text { No Pará, atingidos e nāo atingidos } \\
\text { por inundaçōes }\end{array}$ & $\operatorname{sim}$ & $\begin{array}{l}\text { Somente } \\
\text { para DER }\end{array}$ & $\operatorname{sim}$ & $\operatorname{sim}$ \\
\hline $\begin{array}{l}\text { No Pará, atingidos por inundaçōes } \\
\text { graduais e nāo atingidos por } \\
\text { inundaçōes }\end{array}$ & $\begin{array}{l}\text { Somente } \\
\text { para DER }\end{array}$ & Nāo & $\begin{array}{l}\text { Somente } \\
\text { para DER }\end{array}$ & Nāo \\
\hline $\begin{array}{l}\text { No Pará, atingidos por inundaçōes } \\
\text { bruscas e nāo atingidos por } \\
\text { inundaçōes }\end{array}$ & $\begin{array}{l}\text { Somente } \\
\text { para DER }\end{array}$ & Sim & $\operatorname{sim}$ & $\operatorname{sim}$ \\
\hline $\begin{array}{l}\text { No Pará, atingidos por inundaçōes } \\
\text { bruscas e graduais }\end{array}$ & Nāo & $\begin{array}{l}\text { Somente } \\
\text { para DER }\end{array}$ & Nāo & Nāo \\
\hline $\begin{array}{l}\text { Atingidos por inundaçōes graduais } \\
\text { no Amazonas e no Pará }\end{array}$ & Nāo & Nāo & Nāo & Nāo \\
\hline
\end{tabular}

Fonte dos dados: BRASIL (2015a e b).

\section{Correlações com variáveis quantitativas}

Considerando todos os municípios estudados, o Desempenho Econômico Absoluto (DEA) em 2009 foi menor para os municípios com maior PIB per capita, IDHm e renda média. Já o Desempenho Econômico Relativo (DER) foi menor para os municípios com maior território, PIB per capita, renda média e menor IPH. Uma correlação positiva existente entre o DEA e o DER indica que, no geral, os municípios que apresentaram os maiores prejuízos absolutos também foram os que obtiveram os maiores prejuízos relativos. Considerando as diferentes categorias de municípios atingidos por inundações (graduais ou bruscas; localizados nos estados do Amazonas ou do Pará), percebe-se que as variáveis quantitativas mais importantes foram o PIB, o PIB per capita, a população e o IDHm. Por outro lado, a densidade populacional e a renda média também foram significativas, mas somente para o DEA. Esses resultados estão sintetizados no Quadro 6 e detalhados no Anexo C. 
Quadro 6 - Síntese dos resultados encontrados para as correlações com variáveis quantitativas. Desempenho Econômico Relativo (DER) e Absoluto (DEA). As demais siglas utilizadas são as designadas pelo Quadro 3. O Anexo $\mathrm{C}$ demonstra os resultados detalhados.

\begin{tabular}{|c|c|c|c|c|c|c|c|c|c|c|}
\hline & $\begin{array}{l}\text { DER- } \\
\text { DEA* }\end{array}$ & PIB & $\mathrm{T}$ & Po & PIBc & Dp & IDHm & $\mathrm{Re}$ & IPH & G \\
\hline $\mathrm{Td}$ & + & & - (DER) & & $\begin{array}{c}- \text { (DEA e } \\
\text { DER) }\end{array}$ & & - (DEA) & $\begin{array}{c}- \text { (DEA e } \\
\text { DER) }\end{array}$ & $+(\mathrm{DER})$ & \\
\hline $\mathrm{S}$ & + & $+(\mathrm{DEA})$ & & $+(\mathrm{DEA})$ & - (DEA) & $-(D E A)$ & & & & \\
\hline $\mathrm{D}$ & + & $\begin{array}{c}- \text { (DEA e } \\
\text { DER) }\end{array}$ & & $\begin{array}{c}\text { - (DEA e } \\
\text { DER) }\end{array}$ & $\begin{array}{c}\text { - (DEA e } \\
\text { DER) }\end{array}$ & - (DEA) & - (DEA) & - (DEA) & $+(\mathrm{DER})$ & \\
\hline $\lg$ & + & $\begin{array}{c}- \text { (DEA e } \\
\text { DER) }\end{array}$ & - (DER) & $\begin{array}{c}\text { - (DEA e } \\
\text { DER) }\end{array}$ & $\begin{array}{c}- \text { (DEA e } \\
\text { DER) }\end{array}$ & - (DEA) & - (DEA) & - (DEA) & & \\
\hline $\mathrm{lb}$ & & - (DEA) & & - (DEA) & - (DEA) & - (DEA) & - (DEA) & - (DEA) & & \\
\hline Pal & + & $\begin{array}{c}- \text { (DEA e } \\
\text { DER) }\end{array}$ & & $\begin{array}{c}\text { - (DEA e } \\
\text { DER) }\end{array}$ & $\begin{array}{c}- \text { (DEA e } \\
\text { DER) }\end{array}$ & - (DEA) & $\begin{array}{c}\text { - (DEA e } \\
\text { DER) }\end{array}$ & - (DEA) & & \\
\hline $\begin{array}{c}\text { Am } \\
\text { I }\end{array}$ & + & $\begin{array}{c}- \text { (DEA e } \\
\text { DER) }\end{array}$ & - (DEA) & - (DEA) & $\begin{array}{c}\text { - (DEA e } \\
\text { DER) }\end{array}$ & & & - (DEA) & & \\
\hline $\begin{array}{c}\text { Pal } \\
\mathrm{g}\end{array}$ & + & $\begin{array}{c}- \text { (DEA e } \\
\text { DER) }\end{array}$ & & $\begin{array}{c}- \text { (DEA e } \\
\text { DER) }\end{array}$ & $\begin{array}{c}- \text { (DEA e } \\
\text { DER) }\end{array}$ & - (DEA) & $\begin{array}{c}- \text { (DEA e } \\
\text { DER) }\end{array}$ & - (DEA) & & - (DER) \\
\hline
\end{tabular}

Fontes dos dados: IBGE (2015a); BRASIL (2015a).

\section{PIB, PIB per capita e Renda Média}

Em relação ao DEA, o PIB evidenciou um contraste ao contribuir positivamente nos municípios não atingidos por inundações e negativamente nos atingidos. Dentre os segundos sua relevância foi maior para os municípios atingidos por inundações graduais. Já para o DER, as correlações significativas também foram negativas e mais relevantes para os municípios atingidos por inundações graduais, principalmente os localizados no Estado do Amazonas. O PIB per capita, por outro lado, foi uma variável significativa negativa para praticamente todas as correlações feitas, embora sua relevância tenha sido maior para os municípios atingidos por inundações graduais no Estado do Pará, no caso do DEA e, no Amazonas, no caso de DER.

A "renda média" também apresentou correlação negativa, sendo mais importante para os municípios paraenses - atingidos por inundações bruscas, em termos de DEA; e por inundações graduais, em termos de DER. Ressalta-se que os indicadores PIB, PIB per capita e renda apresentam o problema da não contabilidade da produção voltada ao autoconsumo, de grande relevância na Amazônia, principalmente nos municípios onde predominam a agricultura familiar - cerca de $38 \%$ dos pequenos produtores da região comercializam menos de $50 \%$ do que produzem (OSUNA et al., 2014).

Apesar deste viés, os resultados indicam que, no contexto amazônico, quando ocorrem inundações, os danos econômicos tendem a serem maiores, tanto em termos absolutos como relativos, nos municípios mais ricos. Já quando não ocorrem inundações, os municípios mais ricos são os que apresentam os melhores desempenhos econômicos em termos absolutos, sem distinção estatística, porém, em termos relativos. Em comparação com os resultados encontrados a nível global (HOCHRAINER, 2009; WORLD BANK, 2010), percebe-se uma analogia parcial (quando ocorre um desastre natural): os prejuízos absolutos são maiores nos países mais ricos, assim como, no contexto amazônico, são maiores nos municípios mais ricos; já os prejuízos relativos são maiores nos países mais pobres, enquanto que no contexto amazônico, são menores nos municípios mais pobres.

\section{Tamanho geográfico, população e densidade populacional}

A variável "tamanho geográfico" foi negativamente significativa apenas para o desempenho econômico dos municípios atingidos por inundações graduais, em termos relativos; e localizados no Estado do Amazonas, em termos absolutos. Em nível global, os prejuízos econômicos relativos decorrentes de desastres naturais são maiores nos países pequenos, enquanto que os prejuízos absolutos são maiores nos países grandes (WORLD BANK, 2010). Tal lógica não pode ser aplicada no contexto das inundações graduais na Amazônia, já que os maiores prejuízos, tanto em termos absolutos como relativos, ocorreram nos municípios de maior tamanho geográfico.

As correlações com a variável "população" evidenciaram um contraste. Entre os municípios não atingidos por inundações, os que apresentaram pior 
DEA foram os menos populosos, enquanto que entre os municípios atingidos foram os mais populosos. Nestes últimos, a relevância da "população" foi maior para os municípios atingidos por inundações bruscas. Por outro lado, para o DER, a variável "população" só foi significativa (negativa) para as categorias que incluem municípios atingidos por inundações graduais e localizados no Estado do Pará.

A "densidade populacional" só foi significativa para o DEA, apresentando correlação negativa para os municípios do Estado do Pará. A baixa significância da maioria das correlações provavelmente associa-se ao fato de terem sido contabilizadas a população e a área tanto urbana como rural do município, embora a literatura científica aponte que é principalmente no meio urbano que a variável "densidade populacional" passa a ser importante para vulnerabilidade às inundações (LALL; DEICHMANN, 2012). Por outro lado, muitos impactos negativos podem ter ocorridos na região rural (perda de colheitas, morte de gado etc.), sendo necessária uma análise mais detalhada dos próprios impactos. Uma sugestão seria calcular o desempenho econômico para cada setor da economia (agricultura, comércio, indústria, serviços etc.) ou diferenciando o meio rural do urbano (HOCHAINER, 2009).

\section{IDHm, IPH e Índice de Gini}

As correlações significativas encontradas entre o DEA e o Índice de Desenvolvimento Humano Municipal (IDHm) foram negativas, destacando-se os municípios paraenses, principalmente os atingidos por inundações bruscas. Em termos de DER, o IDHm também foi mais significativo para os municípios paraenses, sendo mais relevante, porém, para os atingidos por inundações graduais. Os indicadores Índices de Pobreza Humana e de Gini apresentaram, no geral, baixa correlação. O primeiro só foi significativo para o DER, de modo que nos municípios atingidos por inundações tal desempenho foi pior naqueles que apresentam maior pobreza, independentemente do tipo de inundação ou da localização. $O$ Índice de Gini foi significativo (negativo) apenas para o DER dos municípios paraenses atingidos por inundações graduais. 0 problema da não inclusão da produção voltada ao autoconsumo também afeta este indicador (SOLIGO, 2012).

Dessa forma, fica claro que os prejuízos econômicos decorrentes de desastres naturais foram pouco afetados por indicadores sociais (como índices de pobreza humana e de Gini). Isso indica que, no contexto amazônico, não existe uma relação direta entre as componentes sociais e econômicas do desenvolvimento sustentável, sendo necessário, portanto, que estas sejam analisadas de forma separada, tal como sugere a escola da sustentabilidade (KESTEMONT, 2010). O PIB, portanto, não pode ser usado como um indicador fiel do desenvolvimento sustentável na Amazônia.

\section{Receitas e transferências orçamentárias}

Dentre os municípios estudados, a maior parte das receitas, em média, se origina de transferências, tanto da União, da ordem de 50 a $60 \%$, como do estado, da ordem de 25 a $30 \%$, enquanto que outras receitas (transferências intermunicipais, impostos municipais etc.), no geral, não ultrapassam 20\%. A ocorrência das inundações em 2009 não alterou essas proporções (Figura 7). Segundo Szlafsztein (2015), essa predominância dos recursos externos na gestão pública dos municípios amazônicos constitui uma das principais vulnerabilidades com relação a prevenção de desastres, pois, além de possibilitar o "desastre moral", reduz a autonomia financeira dos municípios em detrimento do "favoritismo político" e do aumento da dependência em relação ao governo estadual e às diretrizes definidas em nível federal, que, via regra, não são adequadas para as peculiaridades da região. 
Figura 7 - Percentual das transferências da União e do estado para os municípios não atingidos (S) e atingidos (D) pelas inundações de 2009.

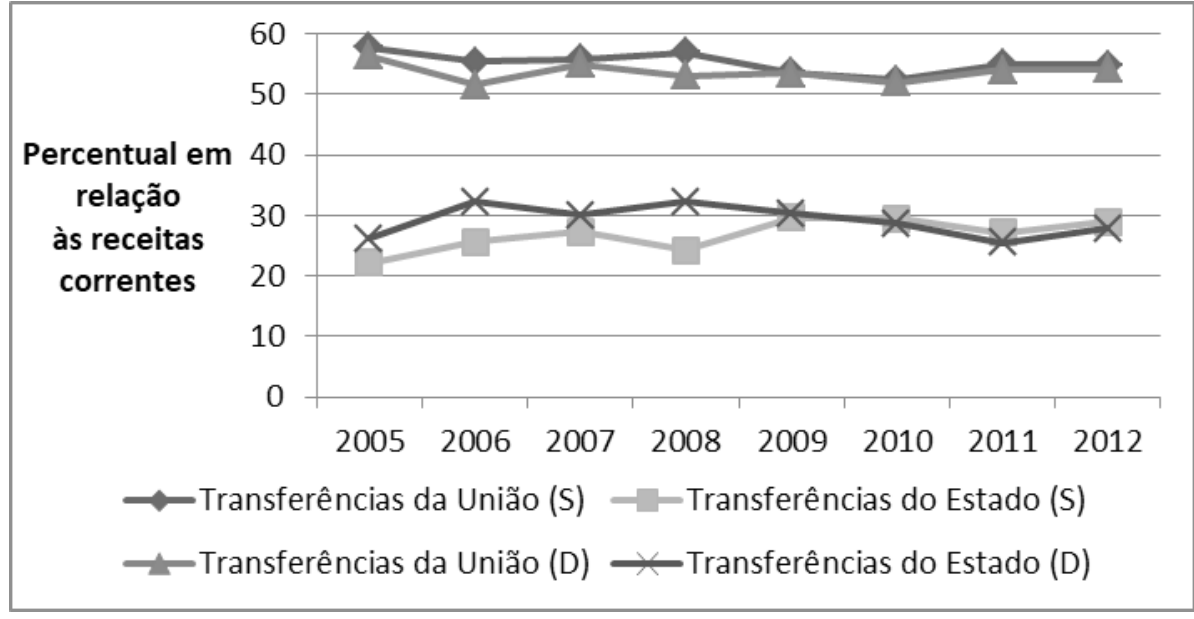

Fonte: BRASIL (2015a).

No período 2005-2012, as médias das receitas e das transferências correntes foram maiores para municípios não atingidos pelas inundações em relação aos atingidos. Por outro lado, em 2009, para ambos os casos, ocorreu uma queda de $12 \%$ das receitas (Figura 7). As correlações mostram que, em termos relativos, essas reduções foram estatisticamente significativas e maiores para municípios atingidos por inundações em relação aos não atingidos; localizados no Amazonas, independentemente de terem sido ou não atingidos por inundações; atingidos por inundações graduais em relação aos municípios não atingidos, porém não em relação aos atingidos por inundações bruscas (Anexo D).

De acordo com Benson e Clay (2004), a ocorrência de desastres naturais pode provocar dois estímulos na receita: tanto uma redução, em virtude da diminuição da arrecadação de imposto, como um aumento, em virtude das transferências de verbas externas. No caso das inundações de 2009 ocorridas na Amazônia, as características da gestão pública municipal, onde grande parte das receitas tem origem externa (governos estaduais e federais), fez com que o primeiro estímulo fosse pouco importante, de modo que a redução das receitas dos municípios atingidos por inundações esteve estritamente associada com a redução das verbas de transferências externas (estaduais e federais). 0 esperado, porém, era que as transferências para esses municípios aumentassem.

Figura 8 - Valor absoluto das receitas correntes dos municípios não atingidos (S) e atingidos (D) pelas inundações de 2009.

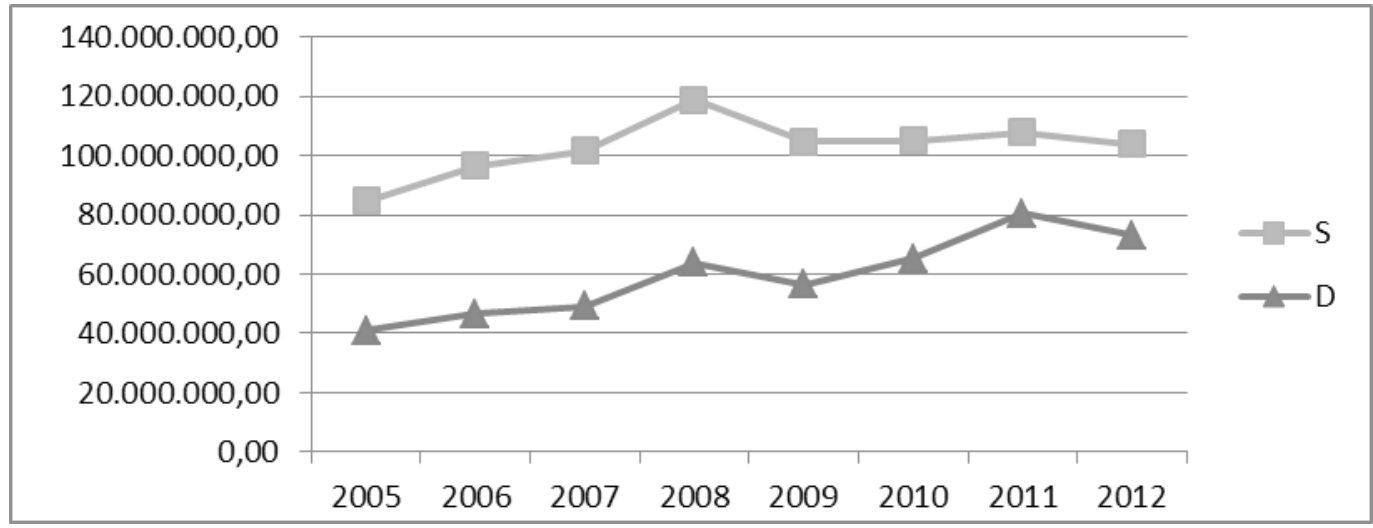

Fonte: BRASIL (2015a). 
Sugere-se, portanto que as inundações não foram o fator determinante para a redução das receitas - uma vez que esta ocorreu tanto nos municípios atingidos como nos não atingidos - e pode estar muito mais associada a outros fatores, como a crise financeira internacional de 2008 (LEAL et al., 2012); ou mesmo à possibilidade de que a grande parte dos recursos federais tenha sido destinada para a região nordeste do Brasil, que também foi atingida por inundações em 2009 (LEAL; SOUZA, 2012). Por outro lado, o fato de essa redução ser estatisticamente maior, em termos relativos, para os municípios atingidos por inundações indica que, quando acontece uma redução das verbas externas (estaduais e/ou federais), são estes os primeiros municípios a receberem cortes de gastos, criando ou acentuando condições de vulnerabilidade destes às inundações.

Outro problema comumente reportado é a realocação das verbas orçamentárias entre diferentes setores/ funções da gestão pública em virtude da ocorrência de desastres naturais (BENSON; CLAY, 2004). Para Nina e Szlafsztein (2014), os desastres naturais ocorridos no Estado do Pará no período de 2000 a 2012 provocaram significativas alterações nas despesas previstas no orçamento do governo estadual, afetando de forma negativa principalmente aquelas destinadas às áreas de meio ambiente e educação, cujas principais consequências foram a redução da eficiência orçamentária, o aumento no prazo de vigência e dos custos de programas de governo e a redefinição das metas previstas. Nesse sentido, há necessidade de uma análise mais detalhada para verificar se este problema também ocorre para as despesas públicas municipais na Amazônia.

\section{Considerações finais}

As inundações ocorridas na Amazônia em 2009 afetaram de forma significativa e negativa o crescimento econômico municipal no curto prazo, mas somente aquelas caracterizadas como bruscas foram capazes de afetar negativamente o crescimento no longo prazo. Estas últimas comprometeram principalmente municípios localizados no sudeste do Estado do Pará, onde o modelo de desenvolvimento e ocupação territorial não foi acompanhado de estratégias de prevenção de risco e redução das vulnerabilidades socioeconômicas às inundações.

O PIB e o tamanho populacional contribuíram de forma negativa para o desempenho econômico dos municípios atingidos por inundações, enquanto que para os municípios não atingidos suas contribuições foram positivas. As variáveis "IDHm" e "Renda média" tiveram maior influência negativa no desempenho econômico absoluto dos municípios atingidos por inundações bruscas, enquanto que, no que se refere ao desempenho econômico relativo, suas influências foram maiores para municípios atingidos por inundações graduais. Já as variáveis "Densidade populacional", "Taxa de urbanização" e "Índice de Gini" foram mais importantes (negativamente) para o desempenho dos municípios paraenses atingidos por inundações graduais - as duas primeiras mais determinantes para o desempenho absoluto e a última para o desempenho relativo.

Os danos econômicos decorrentes das inundações de 2009 na Amazônia, tanto em termos absolutos como relativos, foram maiores nos municípios mais ricos, indicando que o crescimento econômico não está sendo acompanhado de um desenvolvimento em termos qualitativos. As verbas externas (transferências estaduais e federais) foram reduzidas em 2009, o que pode ter acentuado as condições de vulnerabilidade. Por outro lado, ainda há necessidade de futuras pesquisas para verificar se os desastres naturais ocorridos na Amazônia também provocam uma redistribuição das verbas no âmbito da gestão municipal. Os estudos sobre a relação entre o desenvolvimento sustentável e os desastres naturais na Amazônia ainda têm muito a avançar, principalmente no que diz respeito à análise dos impactos: diferenciados por setores econômicos (agricultura, pecuária e serviços); de outros tipos de desastres naturais comuns na região, como secas e incêndios florestais; inclusão de outros indicadores, diferentes do PIB. 
AYSAN, Y.; LAVELL, A. (2014). Disaster risk governance during the HFA implementation period. The United Nations Office for Disaster Risk Reduction, Global Assessment Report on Disaster Risk Reduction. 57 p.

BENSON, C.; CLAY, E. (2004). Understanding the economic and financial impacts of natural disasters. Washington: Disaster Risk Management Series, v.4, 134 p.

BRASIL. (2003). Manual de Desastres: desastres naturais. Brasília: Ministério da Integração Nacional. v. 1, 174 p.

(2015b). Sistema Integrado de Administração Financeira do Governo Federal (SIAFI). Disponível em: <https:// www.tesouro.fazenda.gov.br/siafi>. Acessado em: 5 dez. 2015.

(2015a). Sistema integrado de informações sobre desastres - S2ID. SEDEC. Secretaria Nacional de Defesa Civil. Defesa Civil - Brasil. Disponivel em: <http://s2id.mi.gov.br/>. Acessado em: 12 fev. 2015.

CAVALLO, E.; GALIANI, S.; NOY, I.; PANTANO, J. (2010). Catastrophic natural disasters and economic growth. Inter-American Development Bank, Working Paper Series, n. 183, p. 1-27.

CPRM. (2009). Relatório da cheia 2009. Manaus: Companhia de Pesquisa de Recursos Minerais. 23 p.

CUTTER, S.; BORUFF, B.; SHIRLEY, W. (2003). Social Vulnerability to environmental hazards. Social Science Quarterly, v. 84, n. 2 , p. $242-261$.

ESPINOZA, J.; MARENGO, J.; RONCHAIL, J.; CARPIO, J.; FLORES, L.; GUYOT, J. (2015). The extreme 2014 flood in south-western Amazon basin: the role of tropical-subtropical South Atlantic SST gradient. Environmental Research Letters, v. 9, n. 12, p. 1-9.

FILIZOLA, N; LATRUBESSE, E.; FRAIZY, P.; SOUZA, R.; GUIMARÃES, V.; GUYOT, J. (2013). Was the 2009 flood the most hazardous or the largest ever recorded in the Amazon? Geomorphology, v. 215, n. 1, p. 1-7.

GUJARATI, D.; PORTER, D. (2011). Econometria básica. 5. ed. Porto Alegre: Mcgrau-Hill Companies. 924 p.

HOCHRAINER, S. (2009). Assessing the macroeconomic impacts of natural disasters: are there any? Policy Research Working Paper, n. 4968, p. 1-43.

IBGE. Instituto Brasileiro de Geografia e Estatística. (2015a). Cidades. Disponível em: <http://cidades.ibge.gov.br/ painel/historico . php?lang=\&codmun=150050\&search=paralalmeirim|infograficos:-historico $>$. Acessado em: $5 \mathrm{dez}$. 2015.

(2015b). Sistema IBGE de Recuperação Automática (SIDRA). Disponível em: <http://www.sidra.ibge.gov.br/>. Acessado em: 5 dez. 2015.

JARAMILLO, C. (2009). Do Natural Disasters Have Long-Term Effects On Growth? Documento CEDE, n. 1, p. 1-44, nov. 2009.

KESTEMONT, B. (2010). Les indicateurs de développement durable. Bélgica: Université Libre de Bruxelles. 256 p.

LALL, S.; DEICHAMANN, U. (2012). Density and disasters: economics of urban hazard risk. The World Bank Research Observer, v. 37, n. 1, p. 74-105.

LEAL, A.; SÁ, M.; NASCIMENTO, N.; CARDOSO, W. (2012). Produção mineral no Estado do Pará e reflexos na (re)produção da miséria: Barcarena, Marabá e Paruapebas. Revista Políticas Públicas, v. 16, n. 1, p. 157-167.

LEAL, S.; SOUZA, E. (2012). Desastres naturais sobre a Amazônia e o Nordeste brasileiro associados às enchentes e inundações: o caso de 2009. In: ENCONTRO SUL-BRASILEIRO DE METEOROLOGIA, IV, Gramado-RS, Anais. Gramado/ RS.

LOMBORG, B. (2004). L'ecologiste sceptique: le véritable état de la planète. Paris: COLLECTION DOCUMENTS. 620 p.

MANKIW, N. (2009). Introdução à economia. 5. ed. São Paulo: Cengage Learning. 809 p.

MARENGO, J.; TOMASELLA, J.; ALVES L.; SOARES, W.; RODRIGUEZ, D. (2011). The drought of 2010 in the context of historical droughts in the Amazon region. Geophysical Research Letters, n. 38, p. 1-5.

MATTEDI, M.; BUTZKE, I. (2001). A relação entre o social e o natural nas abordagens de hazards e de desastres. Ambiente e Sociedade, n. 9, p. 1-23. 
NINA, A. S; SZLAFSZTEIN, C. F. (2014). Efeitos de desastres naturais ao desempenho orçamentário do estado do Pará. Novos Cadernos NAEA, v. 17, n. 2, p. 265-285.

NOY, I.; VU, T. (2010). The Economics of natural disasters in a developing country: The case of Vietnam. Journal of Asian Economics, n. 21, p. 345-354.

OSUNA, V.; BÖRNER, J.; CUNHA, M. (2014). Scoping adaptation needs for smalholders in the Brazilian Amazon: a municipal level case study. Change Adaptation Socioecology System, v. 1, p. 12-25.

RADDATZ, C. (2007). Are External Shocks Responsible for the Instability of Output in Low-Income Countries? Journal of Development Economics, n. 84, p. 155-187.

SATRUSTEGUI, K. (2013). Desenvolvimento, subdesenvolvimento, mau-desenvolvimento e pós-desenvolvimento: um olhar transdisciplinar sobre o debate e suas implicações. Revista Perspectivas do Desenvolvimento, n. 1, p. 34-69.

SENA, J.; DEUS, L.; FREITAS, M.; COSTA. L. (2012). Extreme events of droughts and floods in Amazonia: 2005 and 2009. Water Resource Management, v. 26, p. 1665-1667.

SIMONI, J.; LINDOSO, D.; DEBORTOLI, N.; PARENTE, I.; EIDT, G. (2013). Instituições e políticas públicas em territórios da Amazônia: desafios para a capacidade adaptativa e redução de vulnerabilidades. Novos Cadernos NAEA, v. 16, n. 2, p. 45-66.

SKIDMORE, M.; TOYA, H. (2002). Do Natural Disasters Promote Long-run Growth? Economic Inquiry. n. 40, p. 664-687.

SOARES JR., J.; QUINTELLA, R. (2008). Instrumentalização do desenvolvimento: teorias, conceitos e indicadores. Organização \& Sociedade, v. 15, n. 45, p. 61-78.

SOLIGO, V. (2012). Indicadores: conceito e complexidade do mensurar em estudos de fenômenos sociais. Estudos de Avaliação da Educação, v. 23, n. 5, p. 12-25.

SZLAFSZTEIN, C. (2015). Management of natural disasters in the Brazilian Amazon region. Natural Hazards, v. 76, n. 3, p. 1745-1757.

TRINDADE, J.; OLIVEIRA, W. (2013). As finanças dos municípios paraenses: ensaio analítico sobre as receitas de transferências e de suas principais despesas sociais. Revista de Desenvolvimento Regional, v. 18, n. 2, p. 246-273.

VENTURATO-LANDMAM, R.; VALENCIO, N. (2014). "A alagação ofende!": considerações sociológicas acerca de um desastre silente no Alto Juruá, Acre, Brasil. Novos Cadernos NAEA, v. 17, n. 2, p. 239-264.

WORLD BANK. (2010). Natural hazards, unnatural disasters: the economics of effective prevention. Washington, D.C: World Bank Clearance Center Incorporation. 254 p.

XIAO, Y. (2011). Local economic impacts of natural disasters. Journal of Regional Science, v. 51, n. 4, p. 804-820. 
Anexo A: Número dos municípios designados nas Figuras 3 e 4.

\begin{tabular}{|c|c|c|c|c|c|c|c|}
\hline Número & Município & Número & Município & Número & Municipio & Número & Município \\
\hline 1 & Alvarāes & 21 & Jutaí & 41 & Aveiro & 61 & Nova Ipixuna \\
\hline 2 & Anamā & 22 & Lábrea & 42 & Bannach & 62 & $\begin{array}{c}\text { Novo } \\
\text { Repartimento }\end{array}$ \\
\hline 3 & Anori & 23 & Manacapuru & 43 & Belterra & 63 & Óbidos \\
\hline 4 & $\begin{array}{l}\text { Atalaia do } \\
\text { Norte }\end{array}$ & 24 & Manaquiri & 44 & $\begin{array}{l}\text { Brejo Grande } \\
\text { do Araguaia }\end{array}$ & 64 & Parauapebas \\
\hline 5 & Autazes & 25 & Maraā & 45 & Breu Branco & 65 & Porto de Moz \\
\hline 6 & Barreirinha & 26 & $\begin{array}{c}\text { Nova Olinda do } \\
\text { Norte }\end{array}$ & 46 & $\begin{array}{c}\text { Cachoeira do } \\
\text { Arari }\end{array}$ & 66 & Prainha \\
\hline 7 & $\begin{array}{l}\text { Benjamin } \\
\text { Constant }\end{array}$ & 27 & Novo Airāo & 47 & Curionópolis & 67 & Rio Maria \\
\hline 8 & Caapiranga & 28 & Novo Aripuanā & 48 & Curuá & 68 & $\begin{array}{l}\text { Rondon do } \\
\text { Pará }\end{array}$ \\
\hline 9 & Canutama & 29 & Parintins & 49 & $\begin{array}{l}\text { Eldorado dos } \\
\text { Carajás }\end{array}$ & 69 & Rurópolis \\
\hline 10 & Careiro & 30 & $\begin{array}{l}\text { Santo Antônio } \\
\text { do Içá }\end{array}$ & 50 & Faro & 70 & $\begin{array}{c}\text { Santa Cruz do } \\
\text { Arari }\end{array}$ \\
\hline 11 & Coari & 31 & $\begin{array}{c}\text { Sāo Sebastiāo } \\
\text { do Uatumā }\end{array}$ & 51 & $\begin{array}{c}\text { Floresta do } \\
\text { Araguaia }\end{array}$ & 71 & $\begin{array}{c}\text { Santa Maria } \\
\text { das Barreiras }\end{array}$ \\
\hline 12 & Codajás & 32 & Silves & 52 & $\begin{array}{c}\text { Goianésia do } \\
\text { Pará }\end{array}$ & 72 & $\begin{array}{c}\text { Santana do } \\
\text { Araguaia }\end{array}$ \\
\hline 13 & Eirunepé & 33 & Tabatinga & 53 & Gurupá & 73 & $\begin{array}{c}\text { Sāo Félix do } \\
\text { Xingu }\end{array}$ \\
\hline 14 & Envira & 34 & Tefé & 54 & Itaituba & 74 & $\begin{array}{l}\text { Senador José } \\
\text { Porfírio }\end{array}$ \\
\hline 15 & Fonte Boa & 35 & Uarini & 55 & Itupiranga & 75 & Trairāo \\
\hline 16 & Iranduba & 36 & Urucurituba & 56 & Jacareacanga & 76 & Uruará \\
\hline 17 & Itacoatiara & 37 & $\begin{array}{l}\text { Água Azul do } \\
\text { Norte }\end{array}$ & 57 & Jacundá & 77 & $\begin{array}{l}\text { Vitória do } \\
\text { Xingu }\end{array}$ \\
\hline 18 & Itamarati & 38 & Alenquer & 58 & Juruti & & \\
\hline 19 & Itapiranga & 39 & Almeirim & 59 & Marabá & & \\
\hline 20 & Japurá & 40 & Anapu & 60 & Monte Alegre & & \\
\hline
\end{tabular}




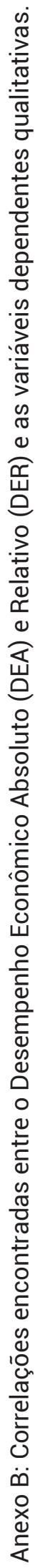

\begin{tabular}{|c|c|c|c|c|c|c|c|c|c|c|c|}
\hline \multirow{3}{*}{$\frac{N}{\tilde{2}}$} & $\widetilde{\curvearrowright}$ & & & & & 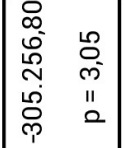 & 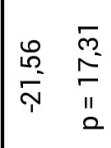 & & & & \\
\hline & $\bar{a}$ & 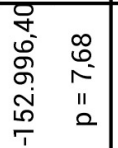 & 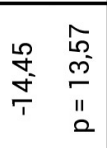 & 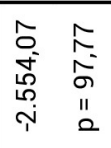 & 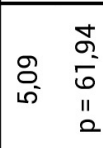 & 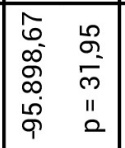 & 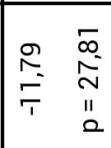 & 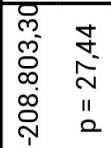 & 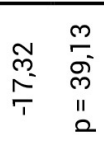 & 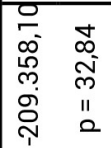 & 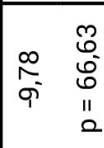 \\
\hline & 遂 & 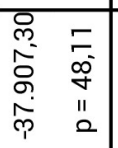 & 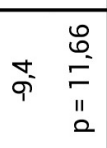 & $\begin{array}{ll}\infty & 0 \\
0 & 0 \\
0 & \mathbb{N} \\
0 & \mathbb{N} \\
T & 11\end{array}$ & 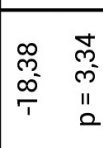 & 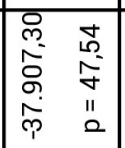 & 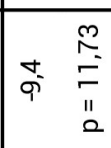 & 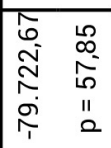 & 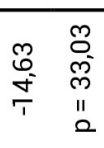 & 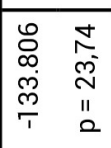 & \begin{tabular}{cc}
0 & $\infty$ \\
\hdashline & 0 \\
$\bar{T}$ & 11 \\
$\bar{T}$ & 0
\end{tabular} \\
\hline \multirow{3}{*}{$\bar{c}$} & $\cong$ & & & & & 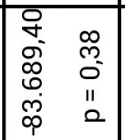 & 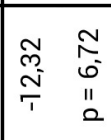 & & & & \\
\hline & $\bar{a}$ & 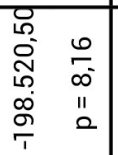 & 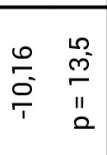 & 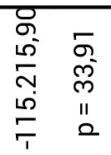 & 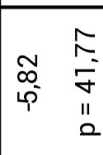 & 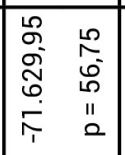 & 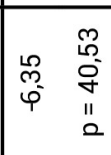 & 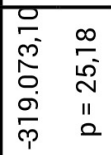 & 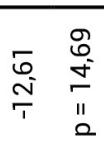 & 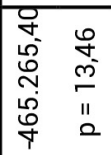 & 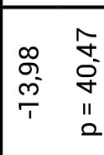 \\
\hline & 요 & 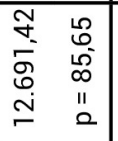 & 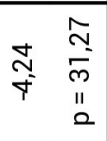 & 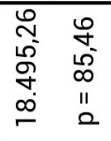 & $\begin{array}{rl} & \infty \\
+ & 0 \\
0 & 11 \\
0 & \\
0\end{array}$ & 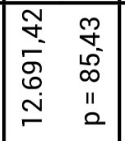 & 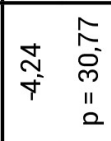 & 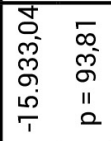 & 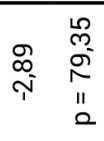 & 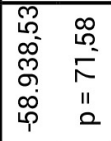 & 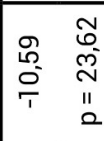 \\
\hline \multirow{3}{*}{$\stackrel{\circ}{\stackrel{\circ}{2}}$} & ๗ & & & & & 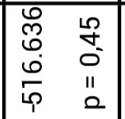 & 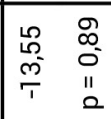 & & & & \\
\hline & $\bar{a}$ & 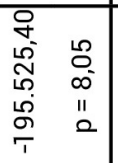 & 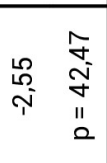 & 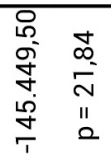 & 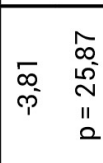 & 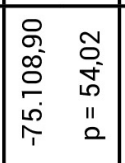 & 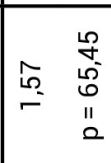 & 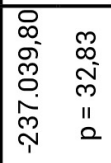 & $\begin{array}{cc}\stackrel{\infty}{\infty} & 0 \\
\stackrel{+}{\sigma} & 0 \\
& 11 \\
& 0\end{array}$ & 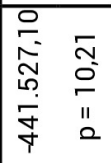 & 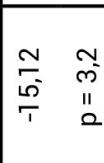 \\
\hline & 용 & 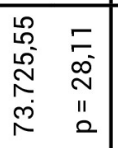 & 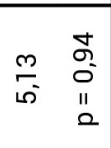 & 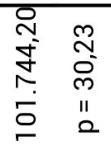 & 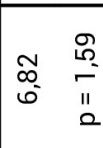 & 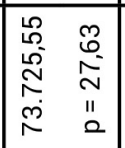 & $\begin{array}{cc}m & 0 \\
m & 0 \\
& 0 \\
& 0 \\
& 11\end{array}$ & 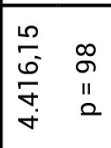 & 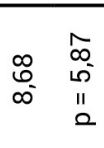 & 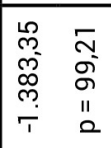 & 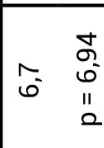 \\
\hline \multirow{3}{*}{ 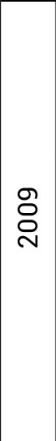 } & ๙ & & & & & 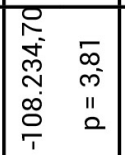 & 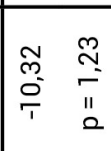 & & & & \\
\hline & $\bar{a}$ & 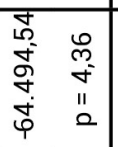 & 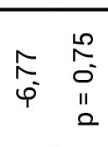 & $\begin{array}{ll}\overline{0} & \overline{0} \\
b & \bar{p} \\
\dot{p} & \bar{m} \\
\dot{p} & 11\end{array}$ & 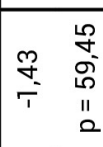 & 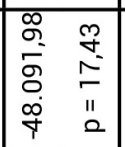 & 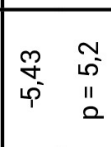 & 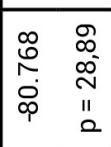 & 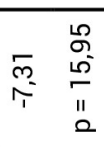 & 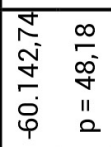 & 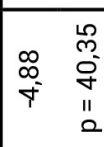 \\
\hline & 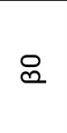 & 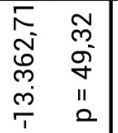 & 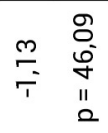 & 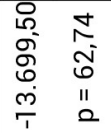 & 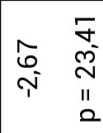 & 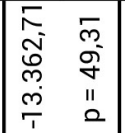 & 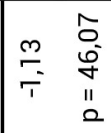 & 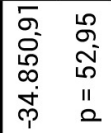 & 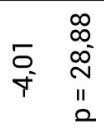 & 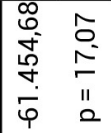 & $\begin{array}{ll} & 0 \\
& 0 \\
0 & 0 \\
0 & 11 \\
& 11\end{array}$ \\
\hline \multirow{2}{*}{ 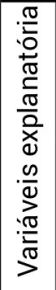 } & $\tilde{x}$ & & & & & $\cong$ & $\underline{\underline{ }}$ & & & & \\
\hline & $\bar{x}$ & 0 & 0 & ${ }_{\alpha}^{\pi}$ & $\stackrel{\sigma}{2}$ & 모 & 모 & $\bar{\alpha}$ & $\bar{\Omega}$ & $\bumpeq$ & $\cong$ \\
\hline \multirow{2}{*}{ 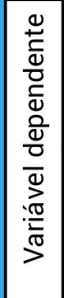 } & $>$ & 㟧 & 䋨 & 㟧 & 給 & 㟔 & 給 & 㟧 & 䍃 & 㟧 & 営 \\
\hline & 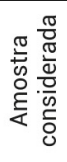 & \multicolumn{2}{|c|}{\ulcorner} & \multicolumn{2}{|c|}{ ஓ } & \multicolumn{2}{|c|}{ 맘 } & \multicolumn{2}{|c|}{ D } & \multicolumn{2}{|c|}{0} \\
\hline
\end{tabular}

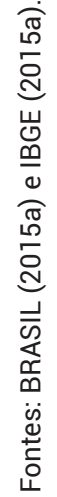




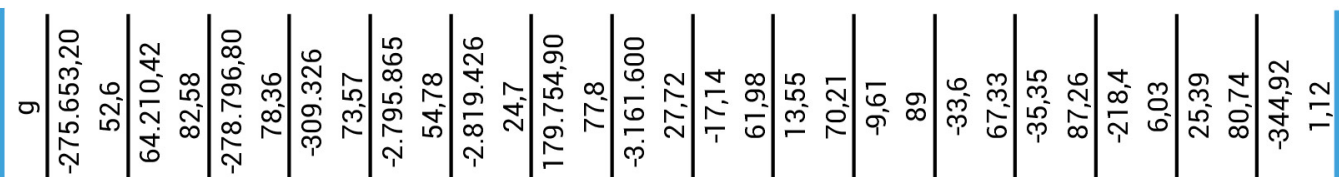
等 을

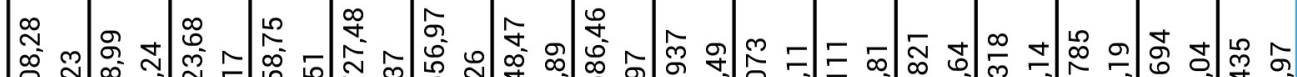

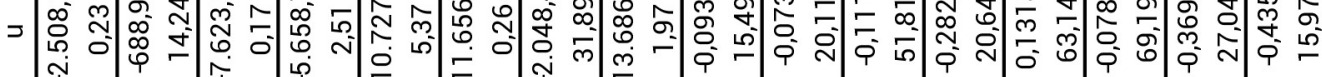

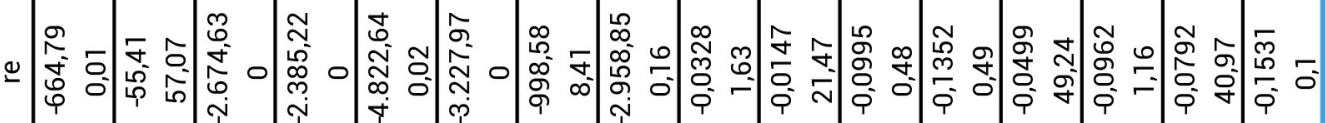

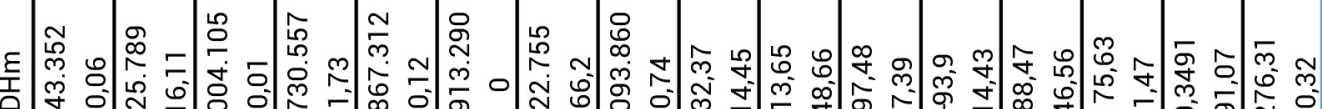

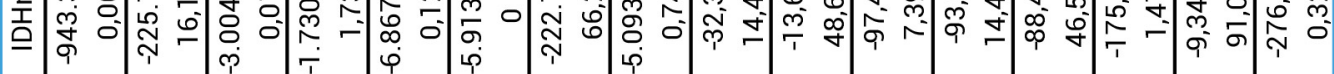

๑

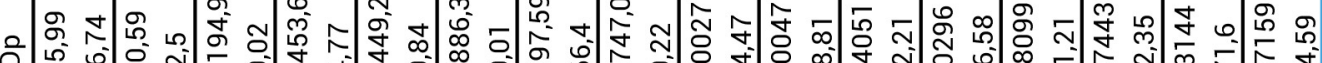
ดी

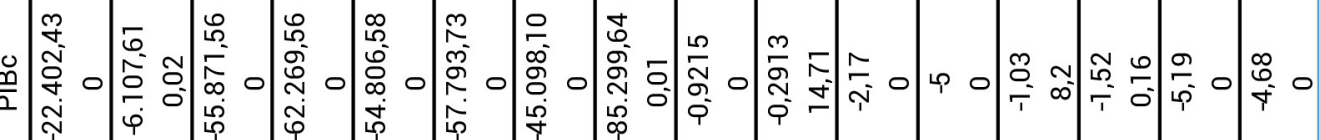
○ 歶员

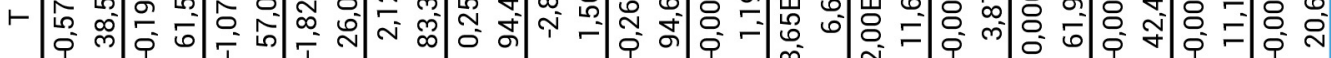

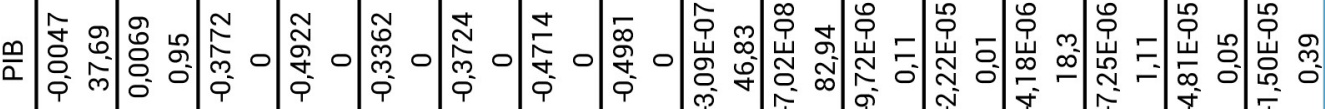

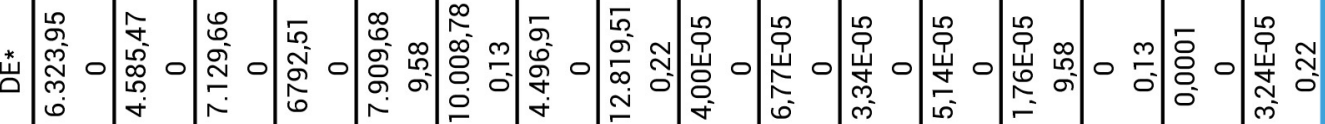

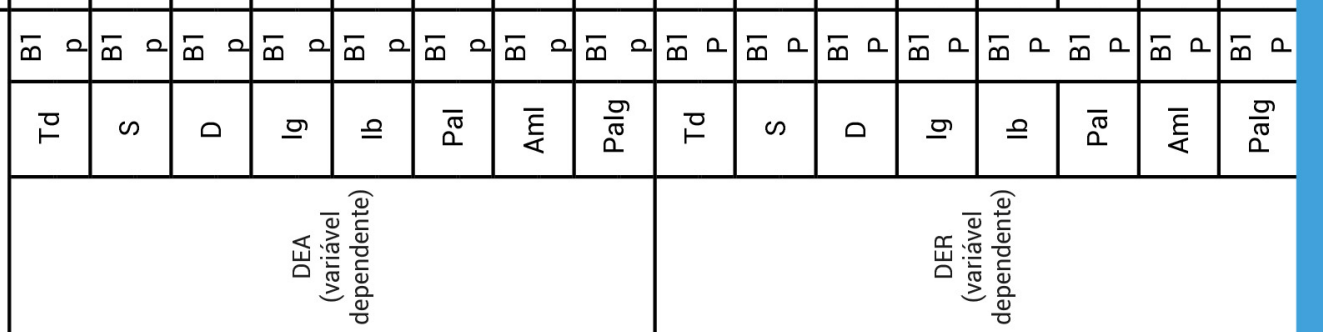

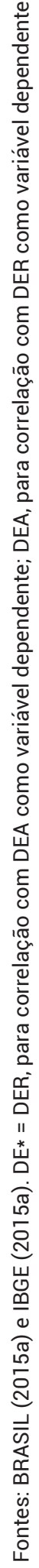




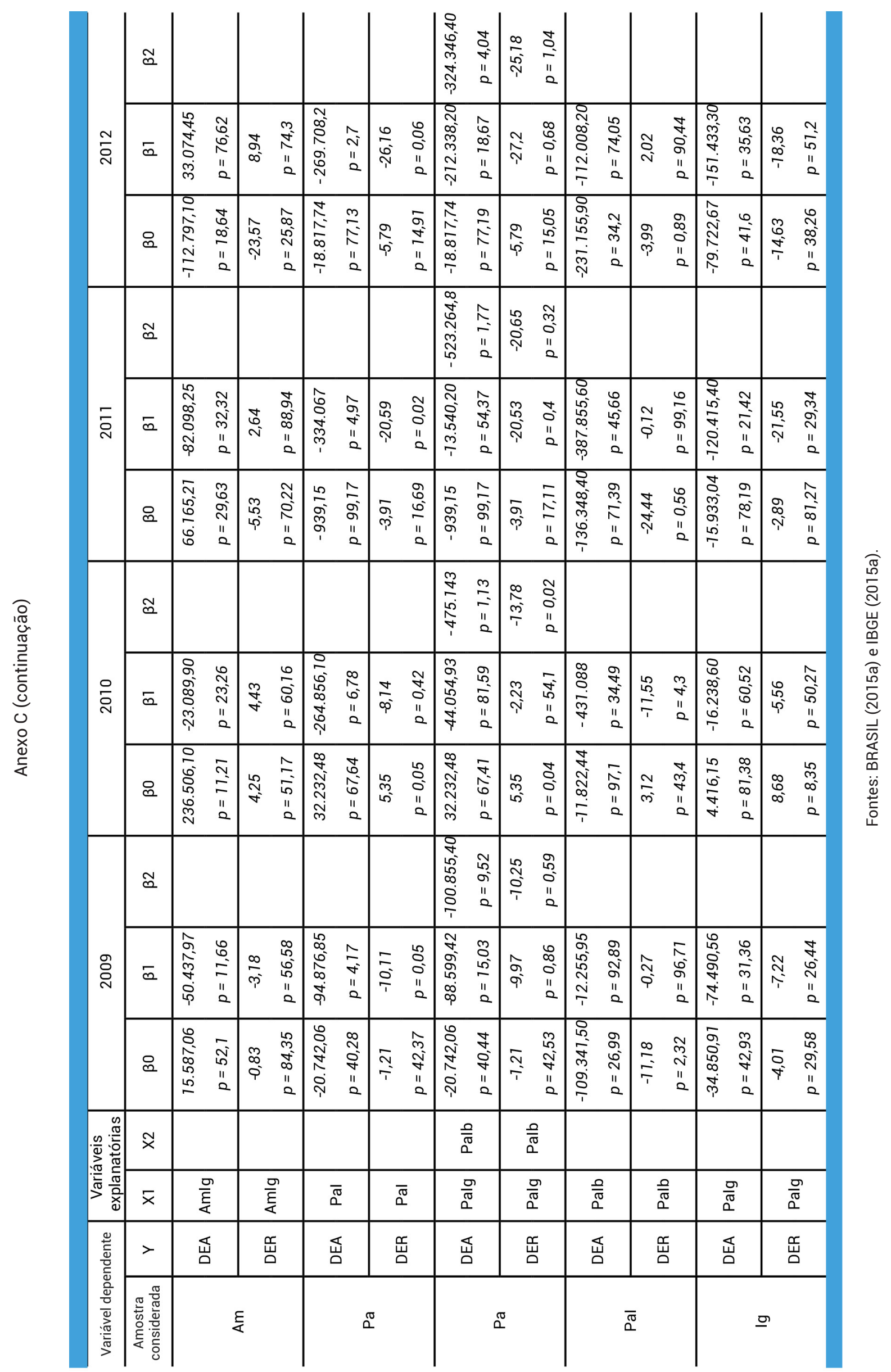


Anexo D: Regressões encontradas entre a diferença das receitas e transferências correntes de 2009 e 2008 e as variáveis dependentes qualitativas. Diferença de receitas absoluta (DRA) e relativa (DRR); Diferença de transferências absoluta (DTA) e relativa (DTR). Os números que estão fora dos parênteses representam os coeficientes angulares. Os números dentro dos parênteses representam os níveis de significância.

\begin{tabular}{|c|c|c|c|c|c|c|c|c|c|c|c|c|c|}
\hline \multirow{2}{*}{\multicolumn{2}{|c|}{$\begin{array}{c}\text { Variável } \\
\text { Dependente }\end{array}$}} & \multicolumn{5}{|c|}{ Variáveis explanatórias } & \multirow{2}{*}{\multicolumn{2}{|c|}{$\begin{array}{c}\text { Variável } \\
\text { Dependente }\end{array}$}} & \multicolumn{5}{|c|}{ Variáveis explanatórias } \\
\hline & & $\beta 0$ & $\beta 1$ & $\mathrm{X} 1$ & $\beta 2$ & $\times 2$ & & & $\beta 0$ & $\beta 1$ & $\mathrm{X} 1$ & $\beta 2$ & $\mathrm{X} 2$ \\
\hline \multirow{2}{*}{$\mathrm{Td}$} & DRA & $\begin{array}{c}4.485 .439 \\
-8,71 \\
\end{array}$ & $\begin{array}{c}- \\
1.500 .592 \\
-72,65 \\
\end{array}$ & D & & & \multirow{2}{*}{$\mathrm{Td}$} & DTA & $\begin{array}{c}2.889 .845 \\
-16,23\end{array}$ & $\begin{array}{c}- \\
1.937 .146 \\
-56,77\end{array}$ & D & & \\
\hline & DRR & $\begin{array}{c}35,76 \\
0\end{array}$ & $\begin{array}{c}-14,45 \\
-4,12\end{array}$ & D & & & & DTR & $\begin{array}{c}31,23 \\
0\end{array}$ & $\begin{array}{l}-14,65 \\
-4,05\end{array}$ & D & & \\
\hline \multirow[t]{2}{*}{$\mathrm{Td}$} & DRA & $\begin{array}{c}232.623 \\
-95,02 \\
\end{array}$ & \begin{tabular}{|c|}
5.336 .494 \\
$-23,41$ \\
\end{tabular} & $\mathrm{~Pa}$ & & & \multirow{2}{*}{$\mathrm{Td}$} & DTA & $\begin{array}{c}304.648,1 \\
0 \\
-91,78 \\
\end{array}$ & $\begin{array}{c}2.695 .369 \\
-44,74 \\
\end{array}$ & $\mathrm{~Pa}$ & & \\
\hline & DRR & $\begin{array}{l}15,45 \\
-0,85\end{array}$ & $\begin{array}{l}22,01 \\
-0,24\end{array}$ & $\mathrm{~Pa}$ & & & & DTR & $\begin{array}{l}15,98 \\
-0,38\end{array}$ & $\begin{array}{l}15,12 \\
-3,55\end{array}$ & $\mathrm{~Pa}$ & & \\
\hline \multirow{2}{*}{$\mathrm{Td}$} & DRA & $\begin{array}{c}4.485 .439 \\
-8,71 \\
\end{array}$ & \begin{tabular}{|c|}
- \\
3.577 .832 \\
$-45,14$ \\
\end{tabular} & $\lg$ & $\begin{array}{c}4.315 .68 \\
2 \\
-54,51 \\
\end{array}$ & $\mathrm{Ib}$ & \multirow{2}{*}{$\mathrm{Td}$} & DTA & $\begin{array}{c}2.889 .845 \\
-16,29 \\
\end{array}$ & \begin{tabular}{|c|}
- \\
2.971 .221 \\
$-42,92$ \\
\end{tabular} & $\lg$ & $\begin{array}{c}958.264,4 \\
0 \\
-86,51 \\
\end{array}$ & $\mathrm{Ib}$ \\
\hline & DRR & $\begin{array}{c}35,76 \\
0\end{array}$ & $\begin{array}{c}-19,09 \\
-1,47\end{array}$ & $\lg$ & $\begin{array}{c}-2,07 \\
-85,45\end{array}$ & $\mathrm{Ib}$ & & DTR & $\begin{array}{c}31,23 \\
0\end{array}$ & $\begin{array}{c}-17,44 \\
-2,37\end{array}$ & Ig & $\begin{array}{l}-4,79 \\
-69,54\end{array}$ & $\mathrm{Ib}$ \\
\hline \multirow[t]{2}{*}{ D } & DRA & $\begin{array}{c}- \\
1.974 .203 \\
-50,45 \\
\end{array}$ & $\begin{array}{c}9.422 .196 \\
-2,3 \\
\end{array}$ & Pal & & & \multirow[t]{2}{*}{ D } & DTA & $\begin{array}{c}- \\
1.385 .693 \\
-59,35 \\
\end{array}$ & $\begin{array}{c}4.442 .947 \\
-21,63 \\
\end{array}$ & $\mathrm{Pal}$ & & \\
\hline & DRR & $\begin{array}{r}9,92 \\
-14,88 \\
\end{array}$ & $\begin{array}{l}22,78 \\
-2,07 \\
\end{array}$ & Pal & & & & DTR & $\begin{array}{l}11,08 \\
-8,81\end{array}$ & $\begin{array}{c}12,47 \\
-20,03\end{array}$ & $\mathrm{Pal}$ & & \\
\hline \multirow{2}{*}{ D } & DRA & $\begin{array}{c}907.606,6 \\
0 \\
-70,62\end{array}$ & $\begin{array}{c}78.935,15 \\
-9,56\end{array}$ & lb & & & \multirow{2}{*}{ D } & DTA & $\begin{array}{c}81.375,43 \\
-96,89\end{array}$ & $\begin{array}{c}3.929 .485 \\
-33,58\end{array}$ & Ib & & \\
\hline & DRR & $\begin{array}{l}16,67 \\
-0,52\end{array}$ & $\begin{array}{c}17,02 \\
-12,82\end{array}$ & lb & & & & DTR & $\begin{array}{r}13,79 \\
-1,39\end{array}$ & $\begin{array}{r}12,65 \\
-27,91\end{array}$ & Ib & & \\
\hline \multirow{2}{*}{$\mathrm{Am}$} & DRA & $\begin{array}{c}3.297 .178 \\
-35,4 \\
\end{array}$ & $\begin{array}{c}- \\
5.271 .381 \\
-25,97\end{array}$ & $\begin{array}{c}\text { Aml } \\
\mathrm{g}\end{array}$ & & & \multirow{2}{*}{ Am } & DTA & $\begin{array}{c}2.656 .838 \\
-40,95 \\
\end{array}$ & $\begin{array}{c}- \\
4.042 .532 \\
-33,95\end{array}$ & $\begin{array}{c}\mathrm{Aml} \\
\mathrm{g}\end{array}$ & & \\
\hline & DRR & $\begin{array}{l}23,39 \\
-1,05\end{array}$ & $\begin{array}{l}-13,46 \\
-24,64\end{array}$ & $\begin{array}{c}\text { Aml } \\
\mathrm{g}\end{array}$ & & & & DTR & $\begin{array}{l}22,99 \\
-1,11\end{array}$ & $\begin{array}{l}-11,91 \\
-30,04\end{array}$ & $\begin{array}{c}\mathrm{Aml} \\
\mathrm{g}\end{array}$ & & \\
\hline \multirow{2}{*}{$\mathrm{Pa}$} & DRA & $\begin{array}{c}4.832 .304 \\
-14,73\end{array}$ & $\begin{array}{c}2.615 .689 \\
-67,61\end{array}$ & Pal & & & \multirow{2}{*}{$\mathrm{Pa}$} & DTA & $\begin{array}{c}2.977 .571 \\
-24,99\end{array}$ & \begin{tabular}{|c|}
$79.682,34$ \\
$-98,69$
\end{tabular} & Pal & & \\
\hline & DRR & $\begin{array}{c}39,55 \\
0\end{array}$ & $\begin{array}{l}-6,85 \\
-45,75\end{array}$ & Pal & & & & DTR & $\begin{array}{c}34,94 \\
0\end{array}$ & $\begin{array}{l}-11,39 \\
-23,32\end{array}$ & $\mathrm{Pal}$ & & \\
\hline \multirow{2}{*}{$\mathrm{Pa}$} & DRA & $\begin{array}{c}4.832 .304 \\
-14,87 \\
\end{array}$ & \begin{tabular}{|c|}
1.262 .561 \\
$-87,81$ \\
\end{tabular} & Palg & $\begin{array}{c}3.968 .81 \\
7 \\
-62,99 \\
\end{array}$ & $\begin{array}{c}\mathrm{Pal} \\
\mathrm{b}\end{array}$ & \multirow{2}{*}{$\mathrm{Pa}$} & DTA & $\begin{array}{c}2.977 .571 \\
-25,16 \\
\end{array}$ & $\begin{array}{c}-711.174 \\
-91,15 \\
\end{array}$ & Palg & $\begin{array}{c}870.538,6 \\
0 \\
-89,18 \\
\end{array}$ & $\begin{array}{c}\mathrm{Pal} \\
\mathrm{b}\end{array}$ \\
\hline & DRR & $\begin{array}{c}39,55 \\
0\end{array}$ & $\begin{array}{c}-8,03 \\
-52,18\end{array}$ & Palg & $\begin{array}{l}-5,86 \\
-61,41\end{array}$ & $\begin{array}{c}\mathrm{Pal} \\
\mathrm{b}\end{array}$ & & DTR & $\begin{array}{c}34,94 \\
0\end{array}$ & $\begin{array}{l}-14,27 \\
-24,91\end{array}$ & Palg & $\begin{array}{c}-8,5 \\
-49,13\end{array}$ & $\begin{array}{c}\text { Pal } \\
\text { b }\end{array}$ \\
\hline \multirow{2}{*}{$\mathrm{Pal}$} & DRA & $\begin{array}{c}6.094 .865 \\
-8,74\end{array}$ & $\begin{array}{c}2.706 .257 \\
-58,5\end{array}$ & Palb & & & \multirow{2}{*}{ Pal } & DTA & $\begin{array}{c}2.266 .397 \\
-45,62\end{array}$ & $\begin{array}{c}1.581 .713 \\
-71,23\end{array}$ & Palb & & \\
\hline & DRR & $\begin{array}{l}31,52 \\
-0,77\end{array}$ & $\begin{array}{c}2,17 \\
-88,59\end{array}$ & Palb & & & & DTR & $\begin{array}{c}20,67 \\
-7,3\end{array}$ & $\begin{array}{c}5,78 \\
-71,42\end{array}$ & Palb & & \\
\hline \multirow[t]{2}{*}{ Ig } & DRA & $\begin{array}{c}- \\
1.974 .203 \\
-51,94 \\
\end{array}$ & $\begin{array}{c}8.069 .068 \\
-11,9 \\
\end{array}$ & Palg & & & $\lg$ & DTA & $\begin{array}{c}1.385 .693 \\
-58,91 \\
\end{array}$ & $\begin{array}{c}3.652 .091 \\
-39,58 \\
\end{array}$ & Palg & & \\
\hline & DRR & $\begin{array}{c}9,92 \\
-14,02\end{array}$ & $\begin{array}{l}21,6 \\
-7,42\end{array}$ & Palg & & & & DTR & $\begin{array}{l}11,08 \\
-7,66\end{array}$ & $\begin{array}{c}9,58 \\
-40,92\end{array}$ & Palg & & \\
\hline
\end{tabular}

